\title{
Aircraft-based observation of meteoric material in lower-stratospheric aerosol particles between 15 and $68^{\circ} \mathrm{N}$
}

\author{
Johannes Schneider ${ }^{1}$, Ralf Weigel ${ }^{2}$, Thomas Klimach ${ }^{1}$, Antonis Dragoneas ${ }^{1,2}$, Oliver Appel $^{1,2}$, Andreas Hünig ${ }^{1,2}$, \\ Sergej Molleker $^{1,2}$, Franziska Köllner ${ }^{1,2}$, Hans-Christian Clemen ${ }^{1}$, Oliver Eppers ${ }^{1,2}$, Peter Hoppe ${ }^{1}$, Peter Hoor ${ }^{2}$, \\ Christoph Mahnke ${ }^{2,1,3}$, Martina Krämer ${ }^{3,2}$, Christian Rolf ${ }^{3}$, Jens-Uwe Grooß ${ }^{3}$, Andreas Zahn ${ }^{4}$, Florian Obersteiner ${ }^{4}$, \\ Fabrizio Ravegnani $^{5}$, Alexey Ulanovsky ${ }^{6}$, Hans Schlager ${ }^{7}$, Monika Scheibe ${ }^{7}$, Glenn S. Diskin ${ }^{8}$, Joshua P. DiGangi $^{8}$, \\ John B. Nowak ${ }^{8}$, Martin Zöger ${ }^{9}$, and Stephan Borrmann ${ }^{2,1}$ \\ ${ }^{1}$ Particle Chemistry Department, Max Planck Institute for Chemistry, Mainz, 55128, Germany \\ ${ }^{2}$ Institute for Atmospheric Physics, Johannes Gutenberg University Mainz, Mainz, 55128, Germany \\ ${ }^{3}$ Institute of Energy and Climate Research, Forschungszentrum Jülich, Jülich, 52425, Germany \\ ${ }^{4}$ Institute of Meteorology and Climate Research, Karlsruhe Institute of Technology (KIT), \\ Eggenstein-Leopoldshafen, 76344, Germany \\ ${ }^{5}$ Institute of Atmospheric Sciences and Climate, ISAC-CNR, Bologna, 40129, Italy \\ ${ }^{6}$ Central Aerological Observatory, Dolgoprudny, Moscow region, 141700, Russia \\ ${ }^{7}$ Institute of Atmospheric Physics, German Aerospace Center (DLR) Oberpfaffenhofen, Wessling, 82234, Germany \\ ${ }^{8}$ NASA Langley Research Center, MS 483, Hampton, VA 23681, USA \\ ${ }^{9}$ Flight Experiments, German Aerospace Center (DLR) Oberpfaffenhofen, Wessling, 82234, Germany
}

Correspondence: Johannes Schneider (johannes.schneider@mpic.de)

Received: 2 July 2020 - Discussion started: 10 August 2020

Revised: 2 December 2020 - Accepted: 2 December 2020 - Published: 26 January 2021

\begin{abstract}
We analyse aerosol particle composition measurements from five research missions between 2014 and 2018 to assess the meridional extent of particles containing meteoric material in the upper troposphere and lower stratosphere (UTLS). Measurements from the Jungfraujoch mountaintop site and a low-altitude aircraft mission show that meteoric material is also present within middle- and lowertropospheric aerosol but within only a very small proportion of particles. For both the UTLS campaigns and the lowerand mid-troposphere observations, the measurements were conducted with single-particle laser ablation mass spectrometers with bipolar-ion detection, which enabled us to measure the chemical composition of particles in a diameter range of approximately $150 \mathrm{~nm}$ to $3 \mu \mathrm{m}$. The five UTLS aircraft missions cover a latitude range from 15 to $68^{\circ} \mathrm{N}$, altitudes up to $21 \mathrm{~km}$, and a potential temperature range from 280 to $480 \mathrm{~K}$. In total, 338363 single particles were analysed, of which 147338 were measured in the stratosphere. Of these total particles, 50688 were characterized by high abundances of magnesium and iron, together with sulfuric ions, the vast ma-
\end{abstract}

jority (48 610) in the stratosphere, and are interpreted as meteoric material immersed or dissolved within sulfuric acid. It must be noted that the relative abundance of such meteoric particles may be overestimated by about $10 \%$ to $30 \%$ due to the presence of pure sulfuric acid particles in the stratosphere which are not detected by the instruments used here. Below the tropopause, the observed fraction of the meteoric particle type decreased sharply with $0.2 \%-1 \%$ abundance at Jungfraujoch, and smaller abundances $(0.025 \%$ $0.05 \%$ ) were observed during the lower-altitude Canadian Arctic aircraft measurements. The size distribution of the meteoric sulfuric particles measured in the UTLS campaigns is consistent with earlier aircraft-based mass-spectrometric measurements, with only 5\%-10\% fractions in the smallest particles detected (200-300 nm diameter) but with substantial $(>40 \%)$ abundance fractions for particles from 300-350 up to $900 \mathrm{~nm}$ in diameter, suggesting sedimentation is the primary loss mechanism. In the tropical lower stratosphere, only a small fraction $(<10 \%)$ of the analysed particles contained meteoric material. In contrast, in the extratropics the 
observed fraction of meteoric particles reached $20 \%-40 \%$ directly above the tropopause. At potential temperature levels of more than $40 \mathrm{~K}$ above the thermal tropopause, particles containing meteoric material were observed in much higher relative abundances than near the tropopause, and, at these altitudes, they occurred at a similar abundance fraction across all latitudes and seasons measured. Above $440 \mathrm{~K}$, the observed fraction of meteoric particles is above $60 \%$ at latitudes between 20 and $42^{\circ} \mathrm{N}$. Meteoric smoke particles are transported from the mesosphere into the stratosphere within the winter polar vortex and are subsequently distributed towards low latitudes by isentropic mixing, typically below a potential temperature of $440 \mathrm{~K}$. By contrast, the findings from the UTLS measurements show that meteoric material is found in stratospheric aerosol particles at all latitudes and seasons, which suggests that either isentropic mixing is effective also above $440 \mathrm{~K}$ or that meteoric fragments may be the source of a substantial proportion of the observed meteoric material.

\section{Introduction}

Aerosol particles in the upper troposphere and lower stratosphere (UTLS) play an important role in Earth's radiative budget: firstly, by direct scattering of sunlight back to space and secondly, by influencing homogeneous and heterogeneous cirrus cloud formation in the upper troposphere (UT). The radiative forcing via aerosol-cloud interaction of ice clouds in the atmosphere was estimated in a model study to be around $+0.27 \mathrm{~W} \mathrm{~m}^{-2}$ (Gettelman et al., 2012). Furthermore, especially under volcanically influenced conditions, aerosol particles in the UTLS provide surfaces for heterogeneous chemical reactions to occur, thereby influencing ozone chemistry (Pitari et al., 2002; von Hobe et al., 2011), and influence the stratospheric circulation due to heating of the stratosphere (Robock, 2000; Kremser et al., 2016). Generally, the dominating sources of aerosol particles and their precursor gases are in the troposphere. Primary emitted particles are for example dust, sea spray, black carbon, and biomass burning particles. Secondary aerosol particles are formed from precursor gases such as organic and sulfur-containing compounds. The sources for both primary and secondary particles can be natural or anthropogenic. In contrast, an exclusively natural source of a certain fraction of atmospheric particles is located outside Earth's atmosphere, causing an ambling but continuous particle import of cosmic origin (Pruppacher and Klett, 1997). The magnitude of cosmic material entering Earth's atmosphere is currently estimated to be about $43 \pm 14 \mathrm{td}^{-1}$ (tonnes per day) (Plane, 2012; CarrilloSánchez et al., 2016). Besides oxygen, major elements of meteoric material are iron $(\mathrm{Fe})$, magnesium $(\mathrm{Mg})$, and silicon $(\mathrm{Si})$, which are found with roughly equal proportions in chondritic meteorites; the most abundant minor elements are carbon $(\mathrm{C})$, sulfur $(\mathrm{S})$, aluminium $(\mathrm{Al})$, sodium $(\mathrm{Na})$, calcium (Ca), and nickel (Ni) (Lodders and Fegley Jr., 1998; Hoppe, 2009; Plane et al., 2015). First detection of magnesium emission lines in the night sky spectrum and the conclusion that at least part of atmospheric magnesium is of meteoric origin were reported by Hicks et al. (1972).

About $8 \mathrm{td}^{-1}$ of the cosmic dust particles (with diameters between $\sim 1$ and $\sim 300 \mu \mathrm{m}$ ) are completely ablated during entry into Earth's atmosphere (Plane, 2003; Carrillo-Sánchez et al., 2016). Quenching evaporated compounds is expected to cause their rapid re-nucleation in the mesosphere to form new particles of the size of a few nanometres, which are commonly referred to as meteoric smoke particles (MSPs) (Saunders et al., 2012; Plane et al., 2015; Hervig et al., 2017). Recent remote-sensing and in situ measurements in the mesosphere indicated that $\mathrm{Fe}$ and $\mathrm{Mg}$ are the main constituents of MSPs (Hervig et al., 2012; Rapp et al., 2012). MSPs have been identified to act as ice nuclei for noctilucent clouds in the mesopause region (e.g. Alpers et al., 2001; Gumbel and Megner, 2009; Megner and Gumbel, 2009; Rapp et al., 2010), and therefore, it is suggested that MSPs have an impact on polar mesospheric summer echoes (Rapp and Lübken, 2004; Megner et al., 2006). As MSPs are too small to sediment gravitationally, it is widely assumed that MSPs are drained from the mesosphere into the stratosphere most efficiently due to the air mass subsidence within the polar winter vortex, on a timescale of months (Plumb et al., 2002; Curtius et al., 2005; Megner et al., 2008; Plane, 2012; Saunders et al., 2012; Weigel et al., 2014; Plane et al., 2015; Kremser et al., 2016). The aerosol particles in the stratospheric aerosol layer (Junge et al., 1961; Junge and Manson, 1961; Kremser et al., 2016) consist mainly of sulfuric-acidwater $\left(\mathrm{H}_{2} \mathrm{SO}_{4}-\mathrm{H}_{2} \mathrm{O}\right)$ droplets (Lazrus et al., 1971; Rosen, 1971; Lazrus and Gandrud, 1974, 1977; Sedlacek et al., 1983; Gandrud et al., 1989; Arnold et al., 1998), but a significant fraction of none-pure sulfate particles has been observed by balloon-borne measurements throughout the stratosphere (Renard et al., 2020). The typical size range of the $\mathrm{H}_{2} \mathrm{SO}_{4-}$ $\mathrm{H}_{2} \mathrm{O}$ droplets ranges between 100 and $200 \mathrm{~nm}$ (Plane et al., 2015; Kremser et al., 2016). It is thought that MSPs partially dissolve in the droplets (Murphy et al., 1998, 2014; Cziczo et al., 2001; Saunders et al., 2012) such that a dilute solution of highly soluble ferrous or ferric sulfate and hydrated magnesium sulfate and silicic acid is formed (Saunders et al., 2012). It was further suggested that silicon and aluminium are present as undissolved granular cores within the droplets (Murphy et al., 2014), which would explain the observations of refractory particles in the Arctic lower stratosphere (Curtius et al., 2005; Weigel et al., 2014).

As was hypothesized in the 1950s (e.g. Jacchia, 1955), shown in measurements from the 1960s (e.g. Hemenway and Soberman, 1962), and recently also further established by Subasinghe et al. (2016), about $95 \%$ of cosmic bodies of sizes greater than $1 \mathrm{~mm}$ in diameter undergo fragmentation upon entering Earth's atmosphere, thereby forming un- 
ablated meteoric fragments (MFs) of presumably submicron size. If such fragments are formed at sufficient particle concentrations, these particles may sediment directly into the lower stratosphere. It has been suggested that MFs may play a role in polar stratospheric cloud (PSC) formation, thereby influencing polar ozone destruction (Voigt et al., 2005; James et al., 2018). Satellite-based observations of PSCs in the Arctic were reproduced by model simulations using CLaMS (Chemical Lagrangian Model of the Stratosphere) but only if heterogeneous nucleation of NAT (nitric acid trihydrate; Grooß et al., 2014) and ice particles (Tritscher et al., 2019) on foreign nuclei were included in the model parameterization. A potential source of the foreign nuclei is meteoric dust (James et al., 2018).

Additionally, certain amounts of cosmic particulate material enter Earth's atmosphere as interplanetary dust particles (IDPs) which, if smaller than $1 \mu \mathrm{m}$ in diameter, are too small to experience any ablative altering during atmospheric entry. The origin of IDPs is mainly attributed to collisions of asteroids, sublimation of comets, and long-decayed cometary trails (Plane, 2003, 2012). In terms of the size-segregated mass influx of cosmic particles (Plane, 2003, 2012), the contribution of submicrometre-sized IDPs to the total atmospheric aerosol particle load is estimated to be small with estimates of about $150 \mathrm{tyr}^{-1}$.

The continuous import of submicrometre IDPs, the sporadic events of meteors' disintegration on atmospheric entry, and the meteoric fragments (with radii $<0.5 \mu \mathrm{m}$; Brooke et al., 2017) contribute to the atmosphere's load of meteoric material, which becomes incorporated and partially dissolved in acidic aerosols (e.g. of $\mathrm{HNO}_{3}$ and/or $\mathrm{H}_{2} \mathrm{SO}_{4}$ at different dilutions with $\mathrm{H}_{2} \mathrm{O}$ ). Bardeen et al. (2008) investigated ablated meteoric material by means of simulations of a coupled general circulation model and a sectional microphysics model. Due to a mesospheric meridional circulation, as Bardeen et al. (2008) revealed, the re-nucleated meteoric ablation material is transported towards the respective winter pole where it subsides within the polar vortex to stratospheric altitudes. According to the study by Dhomse et al. (2013), the nanoparticles originally released at upper-mesospheric altitudes (corresponding to MSPs, which are produced by ablation and recombination in the upper atmosphere) reside for about 4 years in the atmosphere until they are deposited on the surface. The same simulations (Dhomse et al., 2013) predicted the strongest deposition of meteoric ablation material at mid latitudes with a substantially ( $\sim 15$ times) higher efficiency over Greenland than in Antarctica.

The existence of particles containing meteoric material in the lower stratosphere has been shown by direct in situ observations. Mossop (1965) reported on insoluble inclusions found in stratospheric particles sampled at $20 \mathrm{~km}$ by the U2 aircraft and suggested a meteoric origin of these particles. Shedlovsky and Paisley (1966) analysed particles sampled by the U-2 aircraft and detected sulfur, iron, sodium, copper, and chromium. More recently, aircraft-based in situ aerosol mass spectrometry in the tropical and mid-latitude lower stratosphere at altitudes up to $19 \mathrm{~km}$ showed a significant fraction of particles containing meteoric material and sulfuric acid (Murphy et al., 1998, 2014; Cziczo et al., 2001; Froyd et al., 2009). Indirect evidence for the existence of meteoric aerosol particle material in the Arctic lower stratosphere up to $20 \mathrm{~km}$ altitude was reported by Curtius et al. (2005) and Weigel et al. (2014). They measured non-volatile particles that were thermally stable on exposure to $250^{\circ} \mathrm{C}$ and had diameters of $10 \mathrm{~nm}$ to a few micrometres. The fraction of these non-volatile particles increased with altitude up to $70 \%$ at potential temperature levels between 430 and $500 \mathrm{~K}$. Ebert et al. (2016) report on submicrometre particles collected with a cascade impactor in the Arctic stratosphere during the winters of 2010 and 2011 that were analysed for their chemical composition and morphology. They found Fe-rich particles, Ca-rich particles, silicates, silicate-carbon mixed particles, and mixed-metal particles from different sources, such as meteoric material, space debris, and to a lower extent terrestrial sources.

Here we report findings from aircraft measurements of aerosol particle composition in the lower stratosphere at different altitudes, latitudes, and seasons:

- western Europe for spring (March-April 2014) and summer (August-September 2018)

- Mediterranean for summer (August-September 2016)

- Tropics and subtropics (July-August 2017 and August 2018)

- North America and the North Atlantic for winter (January-February 2018).

In all datasets we observed a distinct particle composition type in the lower stratosphere that can be interpreted as particles containing meteoric material, dissolved in or coated by sulfuric acid. We discuss mass spectral composition, size distribution, vertical profiles, latitudinal distribution, and crosstropopause transport of particles containing meteoric material.

\section{Measurements and methods}

\subsection{Field measurements}

This study analyses lower-stratospheric and uppertropospheric aerosol composition measurements taken during five aircraft-based field campaigns, together with two additional composition measurements from the middle and lower troposphere (altitudes below $3600 \mathrm{~m}$ a.s.1.). The individual campaigns are described briefly in the following. The flight tracks of all UTLS research flights included here as well as the locations of the low-altitude measurements are depicted in Fig. 1. An overview about the five UTLS aircraft campaigns is provided in Table 1 . 




Figure 1. Map of the flight tracks of all UTLS research flights used in this study. Additionally the locations of the low-altitude measurements are indicated: Jungfraujoch (3600 ma.s.1.) and the operation range of the NETCARE (Network on Climate and Aerosols: Addressing Key Uncertainties in Remote Canadian Environments) flights (0-3000 ma.s.1.). Please note that dates in this figure are given in the format of year month day.

Table 1. Overview of the five different aerosol composition measurement datasets from the UTLS used in this study. PV: potential vorticity; PVU: potential vorticity unit.

\begin{tabular}{|c|c|c|c|c|c|}
\hline Project & ML-CIRRUS & StratoClim 2016 & StratoClim 2017 & ND-MAX & CAFE-Africa \\
\hline Time & Mar-Apr 2014 & Aug-Sep 2016 & Jul-Aug 2017 & Jan-Feb 2018 & Aug-Sep 2018 \\
\hline Measurement region & Western Europe & $\begin{array}{l}\text { Eastern } \\
\text { Mediterranean }\end{array}$ & Southern Asia & US to Europe & Atlantic Ocean \\
\hline Aircraft & HALO (G550) & M-55 Geophysica & M-55 Geophysica & NASA DC-8 & HALO (G550) \\
\hline Instrument & ALABAMA & ERICA & ERICA & ERICA & ALABAMA \\
\hline $\begin{array}{l}\text { Ablation laser } \\
\text { wavelength }\end{array}$ & $266 \mathrm{~nm}$ & $266 \mathrm{~nm}$ & $266 \mathrm{~nm}$ & $266 \mathrm{~nm}$ & $266 \mathrm{~nm}$ \\
\hline $\begin{array}{l}\text { No. of flights used } \\
\text { in this study }\end{array}$ & 15 & 3 & 8 & 3 & 3 \\
\hline Altitude range $(\mathrm{km})$ & Up to $13.8 \mathrm{~km}$ & Up to $20.2 \mathrm{~km}$ & Up to $20.5 \mathrm{~km}$ & $\mathrm{Up}$ to $11 \mathrm{~km}$ & Up to $14.5 \mathrm{~km}$ \\
\hline Theta range $(\mathrm{K})$ & $276-387$ & $295-490$ & $310-480$ & $276-340$ & $295-380$ \\
\hline Latitude range $\left({ }^{\circ} \mathrm{N}\right)$ & $36.3-57.5$ & $33.4-41.0$ & $20.8-29.5$ & $34.6-68.1$ & $15.0-48.2$ \\
\hline $\mathrm{PV}$ range (PVU) & $0-10$ & $0-24$ & $0-22$ & $0-8$ & $0-10$ \\
\hline $\begin{array}{l}\text { Total number of } \\
\text { single-particle mass } \\
\text { spectra }\end{array}$ & 24833 & 11709 & 138119 & 98598 & 65104 \\
\hline $\begin{array}{l}\text { In stratosphere } \\
\text { (PV > 4 PVU) }\end{array}$ & 6509 & 5092 & 51599 & 73367 & 10771 \\
\hline $\begin{array}{l}\text { Number of mass } \\
\text { spectra dominated by } \\
\text { magnesium and iron }\end{array}$ & 3140 & 2412 & 18688 & 23138 & 3310 \\
\hline $\begin{array}{l}\text { In stratosphere } \\
\text { (PV > 4 PVU) }\end{array}$ & 2986 & 2271 & 18421 & 22050 & 2882 \\
\hline
\end{tabular}




\subsubsection{ML-CIRRUS}

The field campaign ML-CIRRUS (Formation, Lifetime, Properties and Radiative Impact of Mid-Latitude Cirrus Clouds) was conducted in March and April 2014 out of Oberpfaffenhofen, Germany, using the research aircraft HALO (High Altitude and Long Range Research Aircraft). The objective of ML-CIRRUS was to study cirrus clouds by in situ and remote-sensing methods. Including test flights, a total of 16 flights were carried out. Most of the flight time (in total $88 \mathrm{~h}$ ) was spent in the upper troposphere and lower stratosphere. Laser ablation aerosol mass spectrometer data were recorded during 15 flights, the full dataset from which is included in this study. A detailed overview on the mission is given by Voigt et al. (2017).

\subsubsection{StratoClim}

Two aircraft-based research campaigns were conducted within StratoClim (Stratospheric and upper tropospheric processes for better climate predictions), which is a collaborative research project funded by the European Commission. The first StratoClim campaign took place at Kalamata airport, Greece, in August and September 2016. The aim of the mission was to study atmospheric composition in the eastern Mediterranean region, including the remote influence of the Asian monsoon anticyclone (AMA) outflow. Three research flights were conducted. The second StratoClim campaign was a dedicated field activity to investigate the impact of the AMA on the UTLS and took place at the Tribhuvan International Airport of Kathmandu, Nepal, in July and August 2017 (e.g. Höpfner et al., 2019). Eight scientific flights were carried out over Nepal, India, and Bangladesh. The flight paths spanned latitudes from 21 to $27^{\circ} \mathrm{N}$ and longitudes from 79 to $90^{\circ} \mathrm{E}$ (see Fig. 1).

\subsubsection{ND-MAX/ECLIF-2}

The ND-MAX/ECLIF-2 (NASA/DLR-Multidisciplinary Airborne eXperiments/Emission and CLimate Impact of alternative Fuel) mission aimed at the characterization of gaseous and particulate aircraft emissions with a dedicated aircraft-chasing field experiment over southwestern Germany. For this mission, the installation of instrumentation in the NASA DC-8 aircraft took place at Palmdale, CA, USA. Measurements taken during the ferry flights from Palmdale to Germany, on 13 January 2018 and back on 3 and 4 February 2018, were used in this study. These flights reached latitudes up to $68^{\circ} \mathrm{N}$ (see Fig. 1) and longitudes as far as $120^{\circ} \mathrm{W}$ and penetrated deep into the winter stratosphere at around $11 \mathrm{~km}$ altitude.

\subsubsection{CAFE-Africa}

CAFE-Africa (Chemistry of the Atmosphere Field Experiment in Africa) was conducted with HALO in August 2018 out of Sal on the Cabo Verde islands. The main objective was to study the African monsoon outflow in the upper troposphere over the Atlantic Ocean. This study includes only the measurement data from the three research flights that reached the stratosphere, as was inferred from the temperature profiles. These flights took place on 15 and 24 August and 7 September 2018, the latter being the ferry flight back to Germany. The flight tracks of these three flights are included in Fig. 1.

\subsubsection{Additional low-altitude datasets}

To investigate the possible occurrence of meteoric particles in the middle and lower troposphere, we also analyse two additional aerosol composition measurement datasets from lower altitudes: one dataset was obtained during the NETCARE field campaign (Network on Climate and Aerosols: Addressing Key Uncertainties in Remote Canadian Environments; Abbatt et al., 2019), conducted in the Arctic out of Resolute Bay (Nunavut, Canada) in July 2014. A singleparticle mass spectrometer was operated on board the Polar 6 aircraft (Alfred-Wegener-Institut Helmholtz-Zentrum für Polar- und Meeresforschung) and measured at altitudes between 0 and $3 \mathrm{~km}$. Details of the campaign and the mass spectrometer data are given in Köllner et al. (2017). The other lower-altitude dataset is from the mountaintop Jungfraujoch site (3600 ma.s.l.), where a single-particle mass spectrometer was operated during the INUIT-JFJ (Ice Nucleation Research Unit Jungfraujoch) campaign in January and February 2017. The mass spectrometer data are still unpublished, but details on the campaign can be found in Eriksen Hammer et al. (2018) and Gute et al. (2019).

\subsection{Instrumentation and data analysis}

\subsubsection{Aerosol mass spectrometer operated during ML-CIRRUS and CAFE-Africa}

The aircraft-based laser ablation aerosol mass spectrometer (ALABAMA) is described in detail in Brands et al. (2011), Köllner et al. (2017), and Clemen et al. (2020). Briefly, the ALABAMA is a bipolar-ion single-particle analysis instrument that samples aerosol particles from ambient air through a constant-pressure inlet (CPI; Molleker et al., 2020) and an aerodynamic lens. The sampled particle size range (vacuum aerodynamic diameter, $d_{\mathrm{va}}$; DeCarlo et al., 2004) was between about 200 and $1000 \mathrm{~nm}$ during ML-CIRRUS and between 200 and $3000 \mathrm{~nm}$ during CAFE-Africa. Having passed through an aerodynamic lens, the particles are then accelerated into a vacuum chamber. The particles are detected by two $405 \mathrm{~nm}$ laser diodes, and their velocity information is used to determine their vacuum aerodynamic diameter and to trigger a laser shot of the ablation laser (quadrupled Nd:YAG, $266 \mathrm{~nm}$ ) that hits the particles in the ionization region of the bipolar-ion time-of-flight mass spectrom- 
eter. During ML-CIRRUS and CAFE-Africa, aerosol particles were sampled through the HALO aerosol submicrometre inlet (HASI, Andreae et al., 2018). The inlet was mounted on the upper side of the fuselage of the aircraft. Inside the aircraft, the sampled aerosol particles were guided through a $2.9 \mathrm{~m}$ long stainless-steel sampling line with an inner diameter of $5 \mathrm{~mm}$. The calculated transmission efficiency of this sampling line is shown in the Supplement to this paper (Fig. S9 in the Supplement). During ML-CIRRUS, the ALABAMA was operative during 15 flights and analysed more than 24000 ambient aerosol particles (see Table 1). From CAFE-Africa, we analyse only the measurements from the three flights where HALO reached the stratosphere, as was inferred from the temperature profiles. In these three flights the ALABAMA sampled and analysed more than 65000 particles. The higher efficiency and higher upper-size cut-off (see above) of the ALABAMA in CAFE-Africa compared to ML-CIRRUS are due to several instrumental improvements such as a new aerodynamic lens system and delayed ion extraction (Clemen et al., 2020). The ALABAMA was also used in the abovementioned low-altitude field campaigns NETCARE and INUIT-JFJ.

\subsubsection{Aerosol mass spectrometer operated during StratoClim and ND-MAX}

The newly developed mass spectrometer ERICA (ERC - European Research Council - Instrument for Chemical composition of Aerosols) combines single-particle laser ablation and flash vaporization-ionization techniques. It was designed for fully automated operation on the high-altitude research aircraft M-55 "Geophysica" during the StratoClim project and was later reconfigured to be operated on the NASA DC8 during the ND-MAX/ECLIF-2 mission. Here we use only data obtained using the laser ablation part of the ERICA (ERICA-LAMS; laser ablation mass spectrometer). The basic design is similar to that of the ALABAMA, but since this is a newly developed instrument, it is also described here. The aerosol particles are sampled via a CPI (Molleker et al., 2020) and an aerodynamic lens designed for $\mathrm{PM}_{2.5}$ (Peck et al., 2016). In the vacuum chamber, the particles are detected by two laser diodes $(405 \mathrm{~nm})$ and ablated by a pulsed quadrupled Nd:YAG laser emitting at $266 \mathrm{~nm}$. This Nd:YAG laser is operated without a wavelength separator in the laser head and thus emits also a small fraction of the energy in form of the first and second harmonic (1064 and $532 \mathrm{~nm}$ ). The generated ions are analysed in a bipolar-ion time-offlight mass spectrometer (TOFWERK AG, Thun, Switzerland). The size range of the ERICA-LAMS is approximately $100-5000 \mathrm{~nm}\left(d_{\mathrm{va}}\right)$. Particle size was calibrated using PSL (polystyrene latex) particles with diameters between 80 and $5000 \mathrm{~nm}$. The particle detection efficiency at the laser diodes reaches a maximum of about $75 \%$ at $400 \mathrm{~nm}$ and decreases towards lower and higher diameters. The hit rate, defined as the ratio of recorded particle mass spectra to laser shots on particles was about $40 \%$ at diameters around $500 \mathrm{~nm}$, between $5 \%$ and $10 \%$ below $200 \mathrm{~nm}, 20 \%$ at $1000 \mathrm{~nm}$, and below $5 \%$ above $2000 \mathrm{~nm}$ during the StratoClim measurements. During StratoClim, the ERICA was operated on 11 research flights (three in 2016 and eight in 2017), and the ERICA-LAMS analysed about 150000 single particles (see Table 1). During the three ferry flights conducted in the ND-MAX/ECLIF-2 project that are used here, the ERICALAMS recorded more than 98000 single-particle mass spectra.

\subsubsection{Single-particle mass spectrometer data analysis}

The aircraft datasets from all five UTLS campaigns were analysed using a consistent procedure to ensure comparability of the results. First, all data measured during one campaign were merged into one dataset per campaign. This resulted in datasets containing individual spectra information of 11709 particles (StratoClim 2016) to up to 138119 particles (StratoClim 2017) as given in Table 1. These datasets were clustered separately using a fuzzy c-means algorithm (for a general description see Bezdek et al., 1984, and Hinz et al., 1999; for an ALABAMA-specific description see Roth et al., 2016), with a pre-selected number of 20 clusters per campaign. Only cations were considered for the clustering algorithm for two reasons: first, during ML-CIRRUS many anion mass spectra were too noisy. Second, the particle type of interest was found to be mainly characterized by the cation mass spectrum, containing magnesium and iron, as explained in the next section. Further clustering details are given in the Supplement (Sect. S1 and Table S1). For quality assurance and uncertainty estimation, the clustering was repeated using different starting conditions and also different algorithms. The results showed only small deviations in the type of clusters and in the numbers of mass spectra attributed to the clusters (Sect. S1 and Table S2 in the Supplement). Mean mass spectra (anions and cations) were calculated for each cluster and were used for the interpretation of the particle type associated with this cluster. To enable understanding of the different origin of the meteoric-signature particles, meteorological reanalysis data were combined with the measurements, with histograms of relative particle abundance calculated for each cluster, as a function of altitude, potential temperature ("theta"), and potential vorticity (PV).

The datasets from low altitudes (NETCARE at Jungfraujoch) were treated differently: here we searched specifically for mass spectra using selected marker ions that were found in the high-altitude data. This is explained later in detail (Sect. 3.7).

\subsubsection{Auxiliary data}

The existence of steep vertical gradients in water vapour $\left(\mathrm{H}_{2} \mathrm{O}\right)$ and ozone $\left(\mathrm{O}_{3}\right)$ across the tropopause means that correlations of measurements or reanalysis of these species can 
be used to investigate the previous tropospheric influence of a stratospheric air mass. We use independent particle number concentration and particle size measurements to convert the mass spectrometer data to number concentrations. These additional measurement datasets are briefly explained here.

Water vapour was measured during ML-CIRRUS and StratoClim by the airborne Fast In-situ Stratospheric Hygrometer (FISH). This instrument uses Lyman-alpha photofragment fluorescence and is described in detail by Zöger et al. (1999). The detection limit is reported to be below $0.4 \mathrm{ppmv}$; the uncertainty was determined to be about $8 \%-30 \%$ for low $\mathrm{H}_{2} \mathrm{O}$ mixing ratios (1-4 ppmv) and $6 \%-$ $8 \%$ between 4 and 1000 ppmv (Meyer et al., 2015). During ML-CIRRUS, FISH sampled the air through a forwardfacing inlet mounted on the upper fuselage of the HALO aircraft, whereas during StratoClim, the forward-facing FISH inlet was mounted on the side of the fuselage of the Geophysica aircraft (Afchine et al., 2018). The forward-facing inlet also samples cloud droplets and ice crystals, which evaporate in the inlet, such that the FISH measurements refer to total water. We therefore restricted the dataset to non-cloud conditions, by removing the data points where the $\mathrm{H}_{2} \mathrm{O}$ saturation ratio was greater than 0.8 . During ND-MAX/ECLIF-2, water vapour was measured using the diode laser hygrometer (DLH) of the NASA Langley Research Center (LRC; Diskin et al., 2002), which has an uncertainty of $5 \%$. During CAFE-Africa, water vapour was measured by SHARC (Sophisticated Hygrometer for Atmospheric ResearCh), whose detection method is based on direct absorption measurement by a tuneable diode laser (TDL) system. The uncertainty of the SHARC hygrometer is $5 \%$ or \pm 1 ppmv.

Ozone was measured during ML-CIRRUS and CAFEAfrica by the Fast Airborne Ozone monitor (FAIRO), whereas during StratoClim, $\mathrm{O}_{3}$ was measured by the Fast Ozone Analyser (FOZAN-II). FAIRO combines a dry chemiluminescence detector (CI-D) with a two-channel UV (ultraviolet) photometer. The total uncertainty is $1.5 \%$ at $8 \mathrm{~Hz}$ or $1.5 \mathrm{ppb}$, whichever is higher (see Zahn et al., 2012). FOZANII is likewise based on a CI-D and has an uncertainty of less than $10 \%$ (see Yushkov et al., 1999, and Ulanovsky et al., 2001). During ND-MAX, $\mathrm{O}_{3}$ was measured by the UV photometric ozone analyser TE49 (Thermo Scientific), which has an uncertainty of $5 \%$.

Aerosol particle size distributions were measured during both HALO missions using an optical particle spectrometer of the type Grimm 1.129 "Sky-OPC" (optical particle counter), which was installed next to the ALABAMA. The Sky-OPC measured the total particle number concentration and size distribution for particles larger than $250 \mathrm{~nm}$ (manufacturer calibration) in diameter with a reproducibility of $3 \%$, given by the manufacturer. During the StratoClim campaigns, we used a modified Ultra-High Sensitive Aerosol Spectrometer (UHSAS-A), with a particle diameter range from 65 to $1000 \mathrm{~nm}$. The modifications allowed for an airborne application in the stratosphere up to a height of $20 \mathrm{~km}$.
The measurement uncertainties of the UHSAS were determined to $10 \%$ (Mahnke, 2018).

Basic meteorological parameters such as pressure and temperature, as well as aircraft position and altitude, were obtained during ML-CIRRUS and CAFE-Africa from the Basic HALO Measurement and Sensor System (BAHAMAS), during StratoClim from the Unit for Connection with the Scientific Equipment (UCSE) and during NDMAX/ECLIF-2 from the NASA DC-8 facility instrumentation.

\subsection{Meteorological reanalysis}

Meteorological parameters for stratifying the data (e.g. the histograms in Sect. 2.2.3) were derived from the ERAInterim reanalysis (Dee et al., 2011) from the European Centre of Medium Range Weather forecast (ECMWF). For meridional characterization we use equivalent latitude (Lary et al., 1995) from ERA-Interim. For the vertical coordinate, we use potential vorticity from ERA-Interim and potential temperature derived from observed pressure and temperature data. The location of the thermal tropopause (lowest-altitude negative lapse rate) in potential temperature coordinates was taken from ERA-Interim.

\section{Results}

\subsection{Distinct particle type containing magnesium and iron ions}

In all five upper-tropospheric and lower-stratospheric aircraft datasets, the clustering algorithm yielded a type of mass spectra with a mean cation mass spectrum characterized by a high abundance of magnesium $\left(\mathrm{Mg}^{+}, m / z 24\right.$ for the major isotope and $\mathrm{m} / \mathrm{z} 25$ and 26 for the minor isotopes; mass-tocharge ratio) and iron $\left(\mathrm{Fe}^{+}, m / z 56\right.$ for the major isotope and $m / z 54$ for the most abundant minor isotope). Also oxides of $\mathrm{Fe}\left(\mathrm{FeO}^{+}, m / z 72 ; \mathrm{FeOH}^{+}, m / z\right.$ 73) were clearly detected. Additional minor cation peaks include sodium $\left(\mathrm{Na}^{+}\right.$, $m / z 23$ ), aluminium $\left(\mathrm{Al}^{+}, m / z 27\right)$, as well as trace signals of potassium $\left(\mathrm{K}^{+}, m / z 39\right.$ and 41$)$ and calcium $\left(\mathrm{Ca}^{+}, m / z 40\right)$. The mean anion mass spectrum contains almost exclusively sulfuric acid ions, as $\mathrm{HSO}_{4}^{-}\left(m / z\right.$ 97) and $\mathrm{H}_{2} \mathrm{SO}_{4} \mathrm{HSO}_{4}^{-}$ $(\mathrm{m} / z$ 195). Figure 2 shows the averaged bipolar-ion spectra of stratospheric particles (PV $>4$ PVU) from the aircraft mission StratoClim 2017 with the ERICA (Fig. 2a) and from the aircraft mission CAFE-Africa 2018 with the ALABAMA (Fig. 2c). The mean mass spectrum of the Fe and $\mathrm{Mg}$ particle type from the 18421 measurements made during StratoClim 2017 looks remarkably similar to that from the 2882 measurements made during CAFE-Africa 2018. A linear correlation between the mean mass spectra of the $\mathrm{Fe}$ and $\mathrm{Mg}$ particle type measured during CAFE-Africa and StratoClim yielded an $r^{2}$ of 0.97 for both the anions and the cations. The only difference is the detection of $\mathrm{SiO}^{-}(\mathrm{m} / z 44)$ by 
the ERICA during StratoClim 2017 that was missing from the CAFE-Africa observations. This might be due to the additional emission of 1064 and $532 \mathrm{~nm}$ light of the ERICA laser in contrast to the ALABAMA laser such that the ionization probability of Si-containing compounds is higher in the ERICA than in the ALABAMA. Additionally, Fig. 2b and d show the averaged mass spectrum of all other stratospheric particles measured during the two campaigns. These spectra contain anion and cation signals indicating nitrate $\left(\mathrm{NO}_{3}^{-}\right.$, $\mathrm{NO}_{2}^{-}$, and $\mathrm{NO}^{+}$) and several ion signals indicating carbonaceous material $\left(\mathrm{C}^{+}, \mathrm{C}_{2}^{+}, \mathrm{C}_{2} \mathrm{H}_{3}^{+}\right.$, and $\left.\mathrm{C}_{3} \mathrm{H}_{7}^{+}\right)$. The observation that carbonaceous material is found in stratospheric particles agrees with earlier findings by Murphy et al. (1998, 2007, 2014).

Figure 3 shows the fractional abundance of the $\mathrm{Fe}$ and $\mathrm{Mg}$ particle type stratified by altitude, potential temperature, potential vorticity, and ozone, with bin sizes of $500 \mathrm{~m}$ for altitude, $4 \mathrm{~K}$ for potential temperature, $0.5 \mathrm{PVU}$ (potential vorticity units, $1 \mathrm{PVU}=10^{-6} \mathrm{~m}^{2} \mathrm{~s}^{-1} \mathrm{~K} \mathrm{~kg}^{-1}$ ) for potential vorticity, and $50 \mathrm{ppbv}$ for ozone. In total, we detected 3140 particles of this type during ML-CIRRUS, 2412 during StratoClim 2016, 18688 during StratoClim 2017, 23138 during ND-MAX 2018, and 3310 during CAFE-Africa 2018 (see also Table 1). It has to be emphasized here that this fractional abundance refers to the total number of analysed particles by the ERICA and the ALABAMA. Both instruments use a $266 \mathrm{~nm}$ laser for ablation and ionization. Pure sulfuric acid particles are not ablated and ionized at this wavelength, as was previously reported (Thomson et al., 1997; Murphy, 2007) and validated by laboratory measurements with the ERICA. Thus, the fraction of the Fe and Mg particle type given here represents an upper limit and may be overestimated by about $10 \%-30 \%$ because pure sulfuric acid particles are not taken into account. This is discussed in more detail in Sect. 3.5.

During these five aircraft campaigns, the number of the Fe- and Mg-containing particles was largest at high altitudes (upper row in Fig. 3), where a fractional abundance of up to 0.8 was calculated. Similar values (up to 0.6 ) were reported by Murphy et al. (2014) for particles with the same ion signals in the mid-latitude stratosphere. The graphs of potential temperature and potential vorticity (second and third rows) show that the high fractional abundance also corresponds to high values of potential temperature and potential vorticity, indicating that the measurements showing the high fractional abundance of this particle type were taken in the stratosphere.

The tropopause as the boundary between the troposphere and stratosphere is often defined via the temperature lapse rate (known as the thermal tropopause or cold-point tropopause). The potential vorticity has been found to be a better indicator, representing a "dynamical tropopause" in the extratropics (Hoskins et al., 1985; Gettelman et al., 2011). The threshold value used to separate the stratosphere from the troposphere in the extratropics is typically 2 PVU (e.g. Holton et al., 1995), whereas this threshold value increases up to $5 \mathrm{PVU}$ in the subtropics (Kunz et al., 2011). Here we find that the increase of this particle type fraction occurs at about 2 PVU during ND-MAX/ECLIF-2, StratoClim 2016, and CAFE-Africa; at 4 PVU during ML-CIRRUS; and at 8 PVU during StratoClim 2017. In general, PV is not well suited to define the tropopause level in the tropics, and therefore, a potential temperature of $380 \mathrm{~K}$ is typically used instead of PV to define the tropical tropopause (Holton et al., 1995). Notably during the Stratoclim 2017 flights sampling above the AMA, the increase of the iron- and magnesiumcontaining particle fraction is found at $400 \mathrm{~K}$, which is consistent with the high tropopause over the AMA. In the lowest row of Fig. 3, ozone is used as the vertical coordinate. Here, the increase of the particle fraction starts above an ozone mixing ratio of about $150 \mathrm{ppbv}$, indicating the chemical tropopause (Hoor et al., 2002; Zahn and Brenninkmeijer, 2003; Pan et al., 2004). The different tropopause altitudes observed during the individual missions are due to the fact that the height of the tropopause is a function of latitude. The tropical tropopause corresponds to an isentropic surface at a potential temperature level of about $380 \mathrm{~K}$ (Holton et al., 1995), corresponding to a geometric altitude of about $17 \mathrm{~km}$ (Fueglistaler et al., 2009). In the extratropics, the isentropes cross the dynamical tropopause that lies here between 2 and 5 PVU. At polar latitudes the tropopause height is typically around $8 \mathrm{~km}$ (Wilcox et al., 2012).

\subsection{Latitudinal distribution}

To combine all data from the five aircraft campaigns, we binned all particles (in total 338354) by latitude and potential temperature, using $3^{\circ}$ bins for latitude and $20 \mathrm{~K}$ bins for potential temperature (theta), thereby displaying the data in theta-latitude space. The same was done for the ironand magnesium-dominated particle type (in total 50688). Then we calculated the particle fraction of the magnesiumdominated particle type for each bin. Only bins containing more than 10 particles were considered. The result is shown in Fig. 4a (separated graphs for the individual missions are given in Fig. S6 in the Supplement). We also added to the figure the thermal tropopause from the ECMWF dataset, binned into $4^{\circ}$ latitude bins. The median thermal tropopause is given by the thick dashed line and the $25 \%$ and $75 \%$ quartiles by the grey-shaded area. Additionally, a range for the dynamical tropopause is shown, from 2 to $5 \mathrm{PVU}$, by the thin dashed lines. For this, we took all potential temperatures where the potential vorticity ranged between 1.5 and $2.5 \mathrm{PVU}$ (4.5 and 5.5 PVU, respectively) and binned these values into $4^{\circ}$ latitude bins.

The same procedure was used for the other panels in Fig. 4. In Fig. $4 \mathrm{~b}$ the potential temperature relative to the tropopause is used as the vertical coordinate with $10 \mathrm{~K}$ bins. Figure $4 \mathrm{c}$ uses equivalent latitude as the horizontal coordinate. The equivalent latitude of an air parcel is calculated by transforming the contour having the same potential vor- 

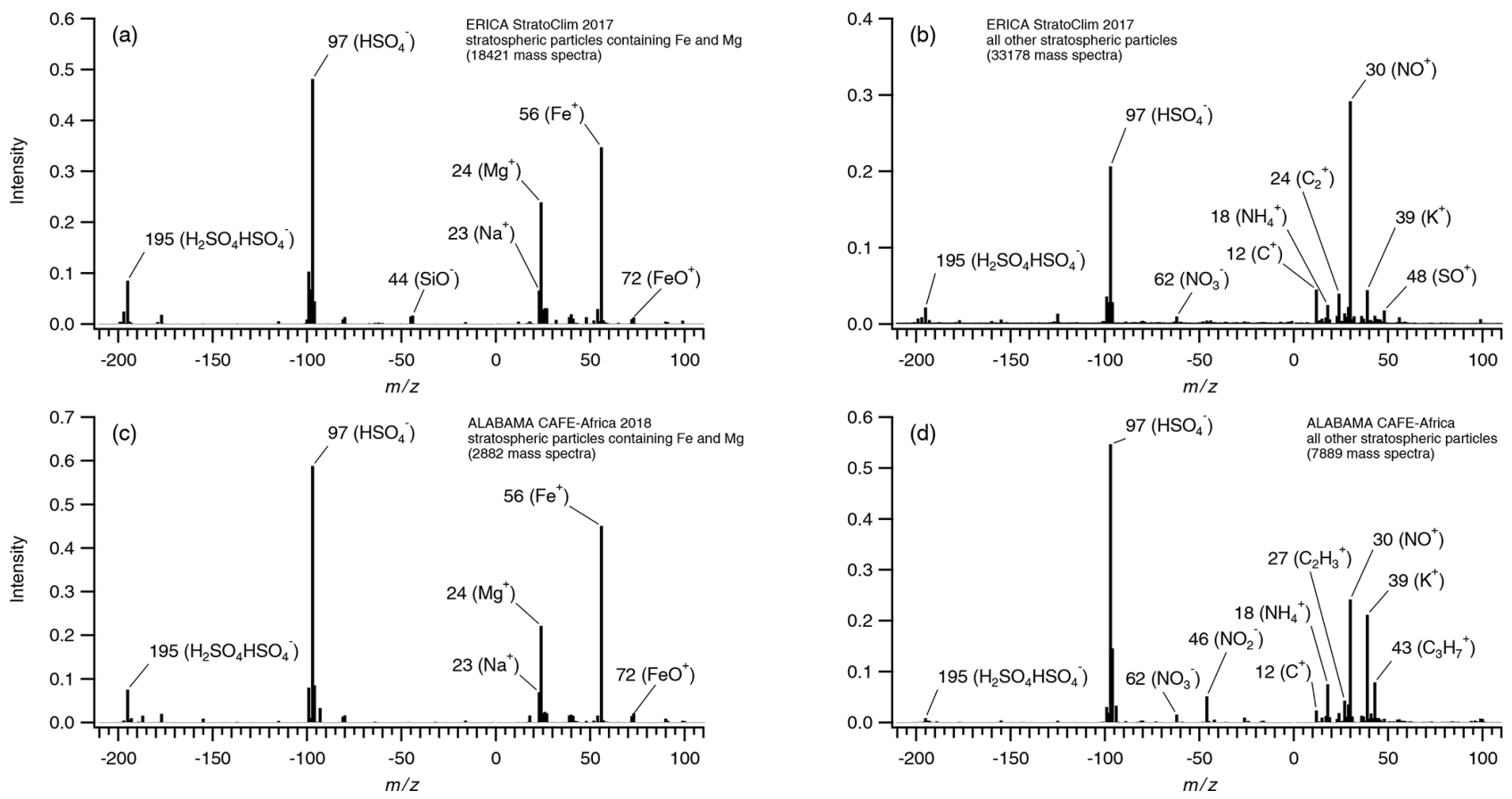

Figure 2. Mean mass spectra of stratospheric particles (PV > 4 PVU). (a, b) StratoClim 2017 (ERICA); (c, d) CAFE-Africa 2018 (ALABAMA). Panels (a) and (c) show the averaged mass spectra of particles of which the positive mass spectra are dominated by iron (Fe ${ }^{+}$ and $\mathrm{FeO}^{+}$) and magnesium $\left(\mathrm{Mg}^{+}\right)$. The two anion as well as the two cation mass spectra of the $\mathrm{Mg}$ - and Fe-dominated particles correlate between the instruments with $r^{2}=0.97$. Panels (b) and (d) show the averaged mass spectrum of all other stratospheric particles.

ticity and potential temperature into a circle centred at the pole. The latitude enclosing this circle is then defined as the equivalent latitude. Since potential vorticity is conserved under adiabatic processes, equivalent latitude can be used to account for reversible adiabatic tracer transport by e.g. planetary waves (Hegglin et al., 2006; Hoor et al., 2010; Krause et al., 2018). Figure $4 \mathrm{~d}$ uses ozone as the vertical coordinate, with $50 \mathrm{ppb}$ ozone bins.

In theta-latitude space (Fig. 4a), the thermal tropopause reaches the $380 \mathrm{~K}$ level at $34^{\circ} \mathrm{N}$ and remains between 370 and $380 \mathrm{~K}$ south of $34^{\circ} \mathrm{N}$. At mid latitudes, the tropopause height decreases until it reaches $300 \mathrm{~K}$ at $60^{\circ} \mathrm{N}$. In thetaequivalent-latitude space (Fig. 4c), the thermal tropopause shows more variation (larger interquartile range), especially between 20 and $40^{\circ} \mathrm{N}$.

All sub-panels in Fig. 4 show that the fraction of the ironand magnesium-dominated particles increases in high and middle latitudes very close to the position of the tropopause but not in the tropics. In theta-latitude space (Fig. 4a), the particle fraction remains as low as in the troposphere between the tropopause (around $370-380 \mathrm{~K}$ ) and $400 \mathrm{~K}$ at latitudes south of $30^{\circ} \mathrm{N}$. Normalizing the potential temperature to the thermal tropopause (Fig. 4b) confirms this observation. In theta-equivalent-latitude space (Fig. 4c), this effect is even more pronounced: south of $35^{\circ} \mathrm{N}$ equivalent latitude, the area between the tropopause and $420 \mathrm{~K}$ shows a very low fraction of the iron- and magnesium-dominated particles. This corresponds to the PV profile of the StratoClim 2017 data from Fig. 3 because the stratospheric tropical data in Fig. 4 are dominated by the StratoClim 2017 dataset. In the AMA, which dominated the geographical region of StratoClim 2017 during the time of the campaign, the air masses are transported upwards between about 360 and $460 \mathrm{~K}$ (Ploeger et al., 2017; Vogel et al., 2019). The observation that the fraction of the iron- and magnesium-dominated particle type increases only above the extratropical tropopause layer or mixing layer (Hoor et al., 2002, 2004; Pan et al., 2004), i.e. $30 \mathrm{~K}$ above the tropopause (Fig. 4b), indicates that the source for this particle type must be above the tropopause because otherwise, the upwelling air masses in the AMA would contain this particle type also at lower potential temperatures. In the stratosphere, the widespread occurrence of high fractions of this particle type over a broad range of equivalent latitudes above $440 \mathrm{~K}$ (Fig. 4c) indicates that this particle type is very homogeneously distributed in the stratosphere. The large equivalentlatitude range is consistent with potential transport between high and low latitudes. From Fig. $4 \mathrm{~b}$ it can be seen that at above a distance of about $40 \mathrm{~K}$ to the tropopause the proportion of the iron- and magnesium-dominated particles does not change substantially with latitude. In Fig. 4 d similar behaviour is observed for ozone levels larger than 300 ppbv. 

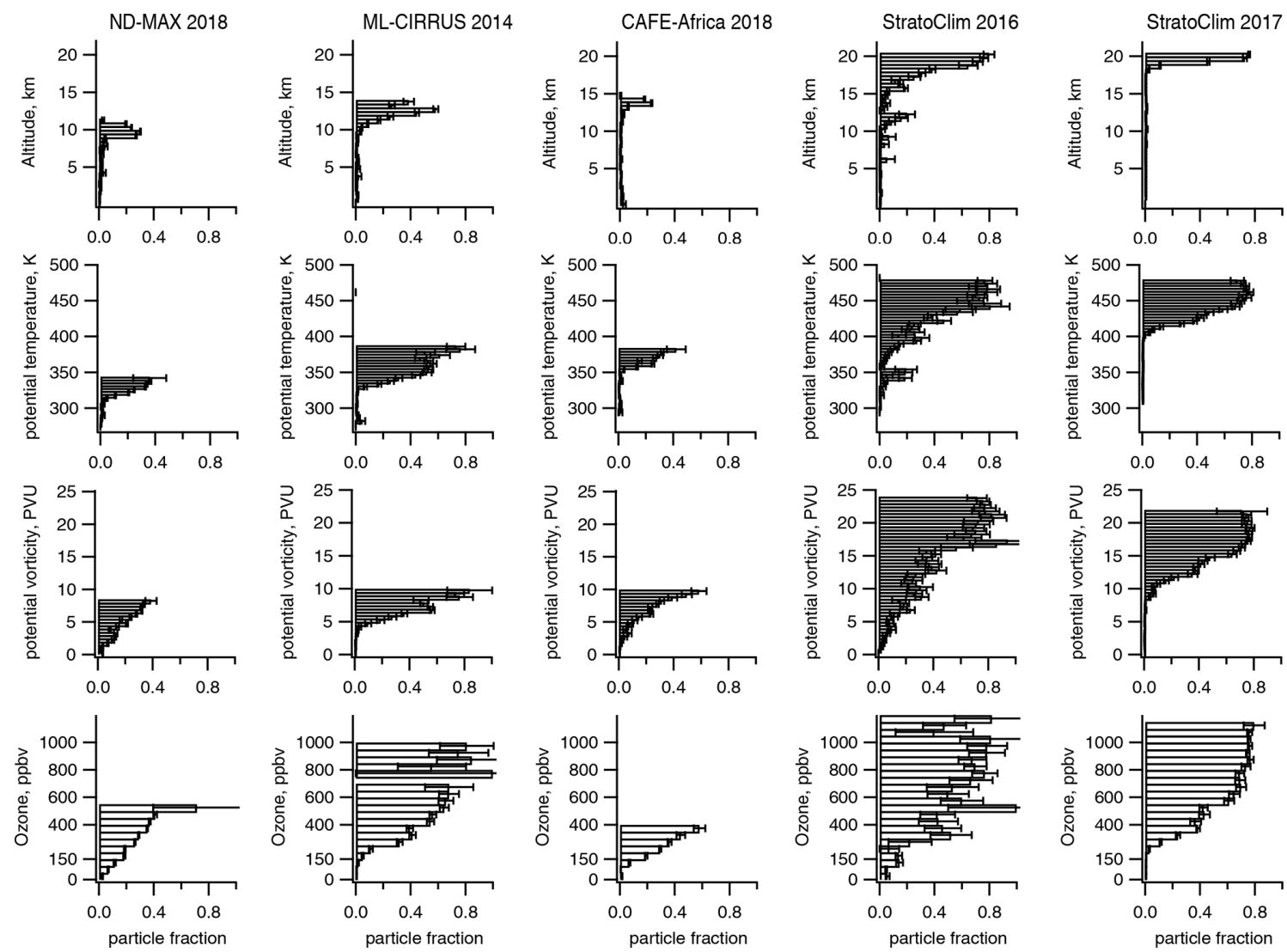

Figure 3. Fractional abundance of particles with cation spectra dominated by magnesium and iron ions. Upper row: as a function of geometric altitude. Second row: as a function of potential temperature. Third row: as a function of potential vorticity (PV). Fourth row: as a function of the ozone mixing ratio. The missions are not sorted in chronological order but rather from low potential temperature (leftmost column) to high potential temperature range (rightmost column). Error bars were calculated from Poisson counting statistics and the propagation of uncertainty.

\subsection{Interpretation as meteoric particles}

From the previous discussion we concluded that the source of this particle type is likely found above the tropopause. The capacity to record bipolar-ion spectra of single particles allows us to show that each particle whose cation mass spectrum is dominated by $\mathrm{Mg}$ and $\mathrm{Fe}$ contains sulfuric acid but no other frequently observed anions like $\mathrm{NO}^{-}, \mathrm{NO}_{2}^{-}, \mathrm{CN}^{-}$, or $\mathrm{CNO}^{-}$. We therefore conclude that the particles we observe consist of meteoric material dissolved in sulfuric acid. This interpretation is fully consistent with the argumentation by Murphy et al. (1998) and Cziczo et al. (2001), who measured stratospheric particle composition using a similar laser ionization mass spectrometer (Particle Analysis by Laser Mass Spectrometry; PALMS) on board the WB-57F high-altitude research aircraft between 5 and $19 \mathrm{~km}$ altitude. Additional PALMS measurements from other campaigns (Cziczo et al., 2001, 2004; Murphy et al., 2007, 2014) as well as laboratory measurements with reference meteoric samples and artificial meteorite particles supported the conclusion that the stratospheric particles with mass spectra dominated by $\mathrm{Mg}$ and $\mathrm{Fe}$ consist of meteoric material dissolved in sulfuric acid (Cziczo et al., 2001). Our cation mass spectra (Fig. 2) show an ion signature very similar to the cation mass spectra from stratospheric particles, dissolved meteorites, and artificial meteorite particles presented in Cziczo et al. (2001). The finding that $\mathrm{Si}$ is observed to a much lesser degree than expected from meteoric composition (roughly equal amounts of $\mathrm{Fe}, \mathrm{Mg}$, and $\mathrm{Si}$ ) was explained by Cziczo et al. (2001) and Murphy et al. (2014) by the low solubility of $\mathrm{SiO}_{2}$ in $\mathrm{H}_{2} \mathrm{SO}_{4}$. Thus, $\mathrm{Si}$ is assumed to be present as a solid inclusion in the particles and is thereby less efficiently ionized compared to the other metals that are dissolved in $\mathrm{H}_{2} \mathrm{SO}_{4}$.

Other sources for this particle type, like aircraft or rocket exhaust, the uplifting of particles (e.g. desert dust) from Earth's surface, and volcanic injection, can be ruled out. The majority of aircraft traffic does not occur at such high altitudes at which the meteoric particles were observed during the StratoClim campaigns. Rocket exhaust can be ruled out because the dominating metal in rocket exhaust particles is expected to be aluminium (Voigt et al., 2013). Single-particle mass-spectrometric measurements of rocket exhaust plumes 



Figure 4. Fractional abundance of particles with cation mass spectra dominated by magnesium and iron ions as a function of potential temperature and latitude (a), as a function of distance to the tropopause and latitude (b), as a function of potential temperature and equivalent latitude (c), and as a function of ozone and latitude (d). The data of all five UTLS aircraft missions have been merged for this figure (in total 338354 analysed particles). Also shown in (a) and (c) is the median thermal tropopause (from ECMWF; TP) along with interquartile range (grey shading) and two dynamical tropopause levels (2 and 5 PVU).

showed ions of chlorine; oxygen; and metals like $\mathrm{Al}, \mathrm{Fe}, \mathrm{Ca}$, $\mathrm{Na}$, and $\mathrm{K}$ but not magnesium (Cziczo et al., 2002). Furthermore, rocket exhaust plumes would hardly lead to the observed uniform and wide geographical distribution of the particle fraction. Volcanic aerosol particles have been measured in the tropopause region and lowermost stratosphere after eruptions of Kasatochi and Sarychev (Andersson et al., 2013). These data show that volcanic aerosol particles contain a larger weight percentage of carbonaceous material than of ash, which is not reflected in our measurements. Furthermore, volcanic ash particles indeed contain not only a number of elements that are abundant in meteorites, like $\mathrm{Fe}, \mathrm{Si}$, $\mathrm{Ca}$, and $\mathrm{K}$, but additionally also elements that are characteristic of crustal material like titanium, which was not observed in our mass spectra. As crustal material that can occur as particles in the troposphere (like soil dust or desert dust) contains the same elements as the stratospheric particles we observed (e.g. $\mathrm{Na}, \mathrm{Mg}, \mathrm{Al}, \mathrm{K}$, and $\mathrm{Fe}$ ), interferences with dust particles in the troposphere might be possible, although the ions $\mathrm{FeO}^{+}$and $\mathrm{FeOH}^{+}(m / z, 72$ and 73) have not been observed in single-particle spectra of mineral dust
(Gallavardin et al., 2008). In the tropical regions, the uplifting of particles from the troposphere into the stratosphere occurs especially in the AMA (Randel et al., 2010; Pan et al., 2016; Yu et al., 2017) and might also carry dust particles into the stratosphere. However, to explain the stratospheric abundance fraction of the observed $\mathrm{Fe}$ - and $\mathrm{Mg}$-rich particle type, this particle type would need to be found already during the upward transport in the AMA, which is clearly not the case (Fig. 4). The mean mass spectra and the vertical profiles of another prominent particle type containing $\mathrm{Fe}, \mathrm{K}$, and $\mathrm{Na}$, as well as smaller signals of $\mathrm{Mg}$ and $\mathrm{Ca}$, is shown in Fig. 5. This particle type was occasionally observed in the stratosphere (ML-CIRRUS, StratoClim 2017, and CAFE-Africa) but in general occurred mainly in the troposphere. We interpret this particle type as an internal mixture of mineral dust, sea spray, sulfate, and nitrate, due to $\mathrm{Na}^{+}, \mathrm{K}^{+}$, and $\mathrm{Fe}^{+}$ cations and chlorine $\left({ }^{35} \mathrm{Cl}^{-}\right.$and $\left.{ }^{37} \mathrm{Cl}^{-}\right)$, nitrate $\left(\mathrm{NO}^{-}\right.$and $\left.\mathrm{NO}_{2}^{-}\right)$, and sulfate $\left(\mathrm{SO}^{-}, \mathrm{SO}_{2}^{-}, \mathrm{SO}_{3}^{-}\right.$, and $\left.\mathrm{HSO}_{4}^{-}\right)$anions. It was therefore not included in the meteoric dataset discussed in this paper. The reason why such particles were found in the stratosphere during ML-CIRRUS is presumably an out- 




Figure 5. Mean mass spectra and vertical profiles of a particle type containing $\mathrm{Na}, \mathrm{K}$, and $\mathrm{Fe}$, with smaller amounts of $\mathrm{Mg}$ and Ca. This type, which was observed in all five high-altitude aircraft missions, does not belong to the meteoric particles, although it was sometimes observed at higher altitudes. It can be interpreted as mineral dust, internally mixed with sea spray and secondary inorganic compounds (nitrate and sulfate). Note that during ML-CIRRUS the anion spectra were noisy due to problems with the high-voltage supply of the ALABAMA.
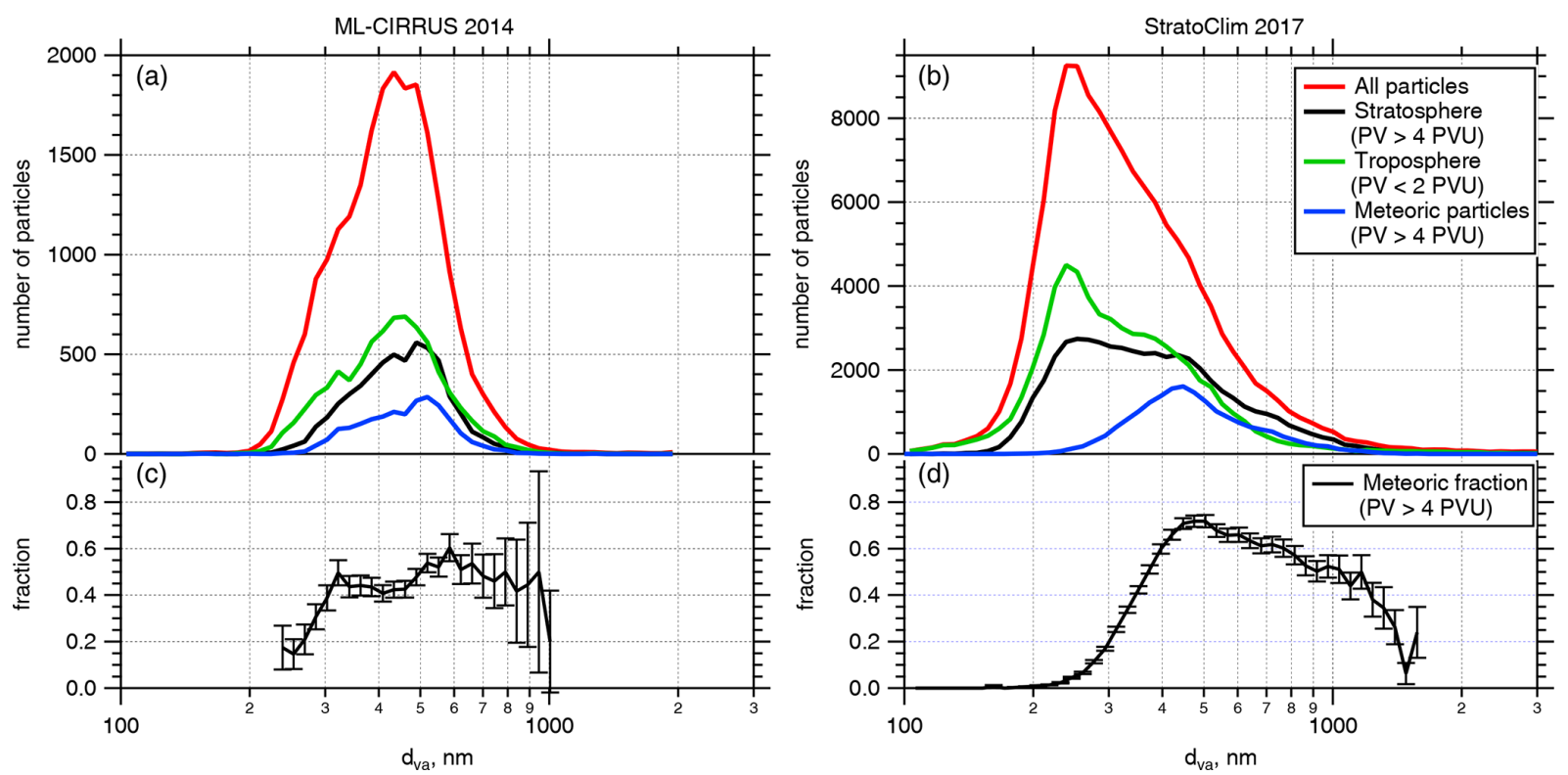

Figure 6. Number of analysed single particles as a function of particle size (vacuum aerodynamic diameter, $d_{\mathrm{va}}$ ) measured during MLCIRRUS 2014 (a, c) and StratoClim 2017 (b, d). Panels (a) and (b) show the absolute number of counted particles per size bin; (c) and (d) show the fraction of particles with a meteoric composition signature in the stratosphere (PV $>4 \mathrm{PVU})$. Error bars were calculated from Poisson counting statistics (number of particles per size bin) and were propagated for the particle fraction. 
break of Saharan dust and its transport towards Europe during the time of the campaign (Weger et al., 2018). During StratoClim 2017 and CAFE-Africa, the vertical uplifting of such particles of tropospheric origin into the stratosphere can most likely be explained by the Asian and African monsoon systems.

\subsection{Size-resolved fraction of meteoric particles}

Both particle mass spectrometers used here (the ALABAMA and ERICA) determine the particle velocity in the vacuum chamber which by laboratory calibration can be converted into the vacuum aerodynamic diameter $\left(d_{\mathrm{va}}\right.$; DeCarlo et al., 2004) of each individual particle. To obtain the size distributions shown in Fig. 6a and b, we used logarithmically equidistant size bins between 100 and $2000 \mathrm{~nm}$ (MLCIRRUS) and 100 and $5000 \mathrm{~nm}$ (StratoClim). These size distributions represent the product of instrument efficiency (inlet transmission, particle detection, and ablation rate) and the ambient particle size distribution. Differences between the measurements with the ALABAMA during ML-CIRRUS and the ERICA during StratoClim 2017 are therefore mainly due to the aforementioned differences in instrumental performance. The particle sizes were separated between tropospheric (PV $<2$ PVU) and stratospheric (PV > 4 PVU) conditions.

In both datasets, the tropospheric particles (green lines) tend to be smaller than the stratospheric particles (black lines). Figure $6 a$ and $b$ also depict the size distribution of the meteoric particles, and Fig. $6 \mathrm{c}$ and d show the ratio between the meteoric particles (also selected for stratospheric conditions) and all stratospheric particles. It turns out that the fraction of meteoric particles is lowest in the smallerparticle size range for both campaigns: in the ML-CIRRUS dataset, the fractional contribution increases from about 0.2 at $250 \mathrm{~nm}$ to about 0.5 at $300 \mathrm{~nm}$ and remains almost constant at 0.5 up to $1000 \mathrm{~nm}$. The StratoClim dataset extends both to smaller and larger sizes and contains a larger number of particles. Here it can clearly be seen that the fraction of meteoric particles is zero at $200 \mathrm{~nm}$, although stratospheric particles are detected even below $200 \mathrm{~nm}$. The meteoric fraction rises to 0.7 at $450 \mathrm{~nm}$ and decreases above that size, down to 0.2 at about $1600 \mathrm{~nm}$. Above that size, only one meteoric particle was detected, although in total 253 stratospheric particles were measured between 1600 and $4400 \mathrm{~nm}$. Thus, the meteoric fraction appears to decrease down to zero above $d_{\mathrm{va}} \approx 1600 \mathrm{~nm}$. This finding is similar to the data shown by Murphy et al. (2014), who found a maximum of meteoric particles at diameters of around 600-700 nm and a decrease down to zero above $d_{\mathrm{va}}=1 \mu \mathrm{m}$. However, the fractions of meteoric particles below $600 \mathrm{~nm}$ is markedly higher in our dataset compared to the study of Murphy et al. (2014). In their dataset, the fraction of meteoric particles decreases from 0.2 at $600 \mathrm{~nm}$ to zero at $500 \mathrm{~nm}$, and no meteoric particles were detected below $500 \mathrm{~nm}$ diameter.
The observed size range of the meteoric particles between about 250 and $1500 \mathrm{~nm}$ indicates that their sedimentation may play an important role in the downward transport of meteoric material through the stratosphere (see Sect. 4). Once the meteoric aerosol particle material has reached altitude levels near the tropopause, its rapid removal out of the stratosphere due to cross-tropopause exchange and cloud formation processes is likely.

\subsection{Particle number concentration}

It is difficult to estimate accurately the absolute number concentration of particles containing meteoric material from the measured particle fraction with our laser ablation mass spectrometers. The main reason is that pure sulfuric acid particles are not ablated and ionized by a laser with a wavelength of $266 \mathrm{~nm}$ because sulfuric acid has a very low absorption cross section for wavelengths larger than about $190 \mathrm{~nm}$ up to visible light (Thomson et al., 1997; Burkholder et al., 2000; Murphy, 2007). Thus, the fraction of particles containing meteoric material will be overestimated due to the presence of pure sulfuric acid aerosol particles in the stratosphere.

The PALMS instrument, using an ablation laser at $193 \mathrm{~nm}$ (Murphy et al., 1998, 2007, 2014; Cziczo et al., 2001) is able to detect pure sulfuric acid particles. The results presented in Murphy et al. (2007) show that the number fraction of the sulfuric particle type ranges between $10 \%$ and $30 \%$ up to $8 \mathrm{~km}$ above the tropopause and at ozone mixing ratios up to $1200 \mathrm{ppb}$. These data were obtained at tropical (Costa Rica) and mid latitudes (Texas). In Murphy et al. (2014), the presented number fraction of sulfuric particles measured at mid latitudes ranges between $10 \%$ and $20 \%$, for ozone mixing ratios up to $1800 \mathrm{ppb}$. We may therefore assume that in our data, where ozone never exceeded $1200 \mathrm{ppb}$, the underestimation of the total analysed particle number due to the presence of pure sulfuric acid particles is about $20 \%$, ranging between $10 \%$ and $30 \%$. This translates into an overestimation of the meteoric particle fraction by the same percentage. However, the variation of the pure sulfuric acid fraction with altitude, potential temperature, latitude, and season is not known well enough to apply a correction to our dataset. Thus, it must be noted that the meteoric particle number fraction as well as the following estimation of the absolute number concentration of particles containing meteoric material may be overestimated by $10 \%-30 \%$.

We estimate the absolute number of meteoric particles by multiplying the meteoric particle fraction by the total particle number concentration measured using an independent absolute particle counting (and sizing) instrument. This process is similar to previous approaches (Qin et al., 2006; Gunsch et al., 2018; Froyd et al., 2019).

For ML-CIRRUS, we used the Sky-OPC optical particle spectrometer (Grimm 1.129). The nominal lower cutoff diameter (manufacturer calibration with PSL particles) is $250 \mathrm{~nm}$. To account for the refractive index of stratospheric 
particles, we performed Mie calculations for refractive indices between 1.43 and 1.45 (Yue et al., 1994). This resulted in a lower cut-off diameter for stratospheric aerosol particles of $285 \mathrm{~nm}$ in diameter (Fig. S10 in the Supplement). The size distributions in Fig. 6 show that for ML-CIRRUS the meteoric fraction is approximately constant above vacuum aerodynamic diameters greater than $300 \mathrm{~nm}$. This value translates into a volume equivalent diameter $\left(d_{\mathrm{ve}}\right)$ of about $180 \mathrm{~nm}$, assuming a density of the lower-stratospheric particles of $1.7 \mathrm{~g} \mathrm{~cm}^{-3}$ (Yue et al., 1994). We also note that the size distribution showed that $99.8 \%$ of all particles counted by the OPC in the stratosphere are below $1000 \mathrm{~nm}$. Thus, we can assume a constant fraction of meteoric particles for the particles counted by the OPC, and therefore multiplying the binned meteoric particle fraction from Fig. 3 with the binned number concentration measured by the OPC should give an estimation of the absolute concentration of meteoric particles larger than $280 \mathrm{~nm}$ for the mid-latitude dataset from MLCIRRUS 2014.

For StratoClim 2017, we used data recorded by the UHSAS (DMT Inc.). According to the size distribution of meteoric particles in Fig. 6, the meteoric particle fraction reaches about $50 \%$ of its maximum fraction at $340 \mathrm{~nm}\left(d_{\mathrm{va}}\right)$. This translates into a volume equivalent diameter $\left(d_{\mathrm{ve}}\right)$ of $200 \mathrm{~nm}$ (assuming the same density for stratospheric aerosol particles as above). Mie calculations using the refractive index range from 1.43 to 1.45 (Fig. S10) yield a lower size limit of $180 \mathrm{~nm}$ (PSL calibration) corresponding to a $d_{\mathrm{ve}}$ of $200 \mathrm{~nm}$ for stratospheric aerosol particles. We therefore used the integrated particle number concentration between 180 and $1000 \mathrm{~nm}$ (PSL calibration) and multiplied this with the fraction of meteoric particles from Fig. 3. This procedure gives an estimation of the absolute concentration of meteoric particles larger than $200 \mathrm{~nm}$ for the tropical dataset from StratoClim 2017.

Figure 7 shows the total particle concentrations for the two missions named above as a function of altitude, potential temperature, and potential vorticity for the upper troposphere and lower stratosphere. The $6 \mathrm{~s}$ raw data are shown along with binned mean, median, and quartiles. The number concentrations of about $1 \mathrm{~cm}^{-3}$ at $20 \mathrm{~km}$ for particles greater than $200 \mathrm{~nm}$ are in agreement with previous balloonborne stratospheric measurements (Deshler et al., 2003; Renard et al., 2020). The calculated meteoric particle concentrations are shown as binned median values with quartiles. The highest absolute number concentrations of meteoric particles range around $0.8 \mathrm{~cm}^{-3}$ (referring to ambient pressure and temperature). During StratoClim 2017 these values were reached above $20 \mathrm{~km}$, potential temperatures of $50 \mathrm{~K}$, and potential vortices of 17 PVU. During ML-CIRRUS, values of $0.8 \mathrm{~cm}^{-3}$ are only reached at $\mathrm{PV}>9 \mathrm{PVU}$, whereas in altitude and potential temperature coordinates the concentrations reach only $0.4 \mathrm{~cm}^{-3}$. Nevertheless, the absolute range of meteoric particle concentration is very similar for both datasets, although the calculation of the meteoric particle concentration relies on different size ranges of the optical instruments, is based on several assumptions, and suffers from various uncertainties, as detailed above.

\subsection{Transport mechanism for cross-tropopause exchange}

To investigate the downward transport of meteoric particles through the tropopause into the troposphere, we use the tracer-tracer correlation of ozone as a stratospheric tracer and water vapour as a tropospheric tracer. Tracer-tracer scatterplots have been widely used to identify mixing between the troposphere and stratosphere (Fischer et al., 2000; Hoor et al., 2002; Pan et al., 2004; Marcy et al., 2007; Gettelman et al., 2011; Krause et al., 2018). In such scatterplots irreversible tracer exchange shows up as lines connecting the respective mixing ratios of the initial unmixed reservoir air parcels and are termed mixing lines (Hoor et al., 2002). The occurrence of mixing lines is a clear indication for mixing between stratospheric and tropospheric air. It is more common to use carbon monoxide as a tropospheric tracer, but because it was not measured during ML-CIRRUS, we use water vapour for which the applicability to serve as a tropospheric tracer in tracer-tracer correlations has been shown by Gettelman et al. (2011), Pan et al. (2014), and Heller et al. (2017). High ozone values indicate stratospheric air (vertical branch); high $\mathrm{H}_{2} \mathrm{O}$ values indicate tropospheric air (horizontal branch).

Figure 8 shows the tracer-tracer correlations between ozone and $\mathrm{H}_{2} \mathrm{O}$ for ML-CIRRUS, StratoClim 2017, NDMAX/ECLIF-2, and CAFE-Africa. The data coverage of $\mathrm{O}_{3}$ and $\mathrm{H}_{2} \mathrm{O}$ during StratoClim 2016 was not sufficient (see Fig. S7 in the Supplement). The left panels show all data from the trace gas measurements, colour-coded by equivalent latitude. The mid-latitude data from ML-CIRRUS (Fig. 8a) show a clear separation between air masses of mid-latitude and tropical origin. The mixing lines, indicating irreversible mixing between the troposphere and the stratosphere, have equivalent latitudes $>30^{\circ} \mathrm{N}$, whereas the green-coloured data points that correspond to tropical air masses (equivalent latitude $<30^{\circ} \mathrm{N}$ ) do not show such mixing. Figure $8 \mathrm{~b}$ shows the $\mathrm{H}_{2} \mathrm{O}$ and $\mathrm{O}_{3}$ data for all sampled particles (grey) and for all meteoric particles (black). As expected, the density of black data points is highest in the stratospheric branch of the tracer-tracer correlation. Figure $8 \mathrm{c}$ shows the fraction of meteoric particles within an ozone-water-vapour grid. Mixing between extratropical stratospheric and tropospheric air is indicated by mixing lines with equivalent latitudes $>30^{\circ} \mathrm{N}$, connecting regions of elevated extratropical and low stratospheric $\mathrm{H}_{2} \mathrm{O}$ values. Isentropic mixing between dry air which passed the Lagrangian cold point (and therefore exhibits $\mathrm{H}_{2} \mathrm{O}$ mixing ratios $<6 \mathrm{ppmv}$ ) and higher latitudes is indicated by the vertical branch starting at $\mathrm{O}_{3}$ mixing ratios $<150 \mathrm{ppbv}$, connecting the dry upper tropical troposphere with the stratosphere. 

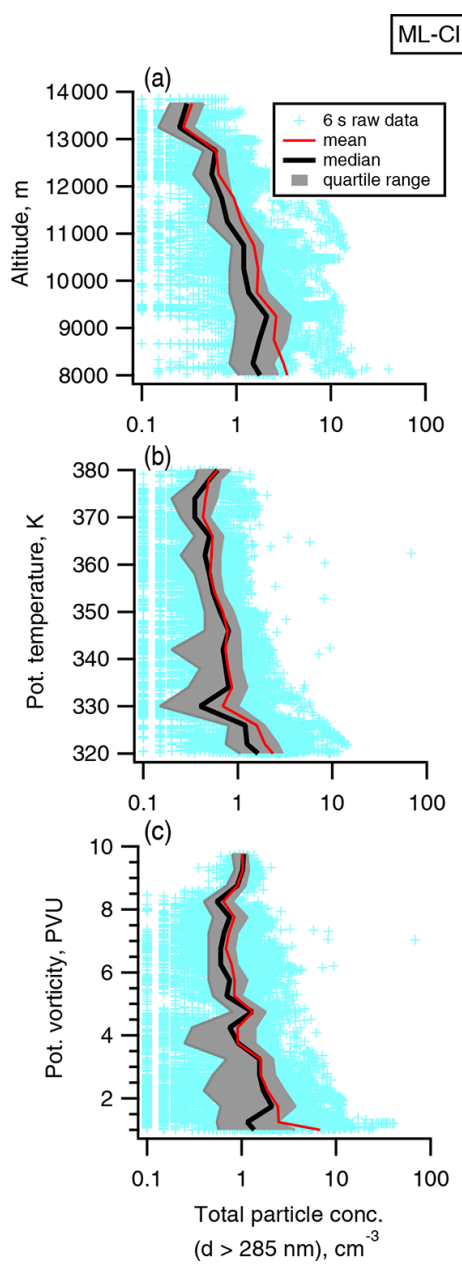



(e)

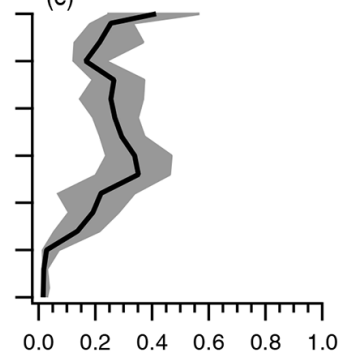

$(f)$

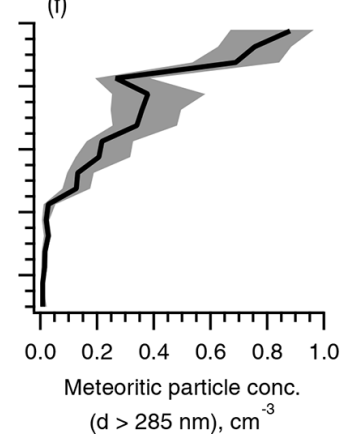

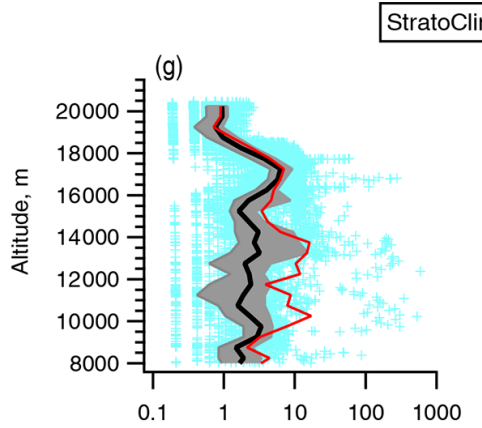

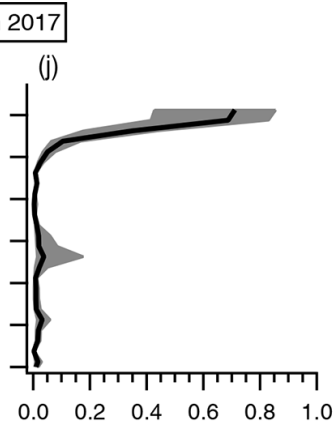

(k)
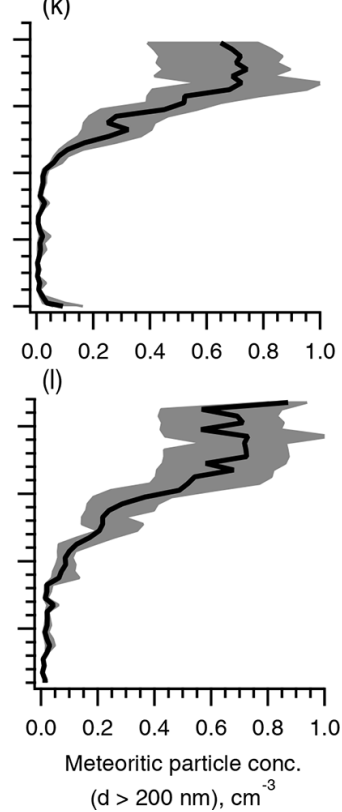

Figure 7. Total particle number concentrations measured during ML-CIRRUS $2014\left(d_{\mathrm{ve}}>285 \mathrm{~nm}\right.$, a-c) and StratoClim $2017\left(d_{\mathrm{ve}}>200 \mathrm{~nm}\right.$, g-i) along with calculated number concentrations of particles containing meteoric material (ML-CIRRUS 2014: d-f; StratoClim 2017: j-l). Data are shown for the upper troposphere and lower stratosphere (altitude $>8 \mathrm{~km}$, potential temperature $>320 \mathrm{~K}$, PV $>1 \mathrm{PVU}$ ). Light-blue markers: $6 \mathrm{~s}$ raw data; red line: mean; black line: median; grey area: quartiles (25\% and $75 \%)$.

In the StratoClim 2017 dataset (Fig. 8d-f) no mixing lines were observed. Only very few meteoric particles are observed in the tropospheric branch of the $\mathrm{O}_{3}-\mathrm{H}_{2} \mathrm{O}$ plot (below 100 ppbv $\mathrm{O}_{3}$ ), showing that downward mixing of meteoric particles from the stratosphere does not occur in the upwelling tropical air masses of the AMA (see also Fig. 4).

The datasets of ND-MAX/ECLIF-2 (Fig. 8g-i) and CAFE-Africa (Fig. 8j-1) appear similar in this tracer-tracer correlation, although the geographic latitudes and seasons of the two campaigns were very different. In both missions, the highest observed $\mathrm{O}_{3}$ values are $400-500$ ppbv, and the equivalent latitudes reach up to $60-70^{\circ} \mathrm{N}$ in the stratosphere. Both datasets show a high degree of stratospheretroposphere mixing, as can been seen from the higher $\mathrm{H}_{2} \mathrm{O}$ mixing ratios at $\mathrm{O}_{3}$ levels between 100 and 200 ppbv, corresponding to the mixing lines observed during ML-CIRRUS. Along these mixing lines, meteoric particles are frequently observed, even at tropospheric altitudes where water vapour mixing ratios of $>1000 \mathrm{ppmv}$ are reached.

\subsection{Detection of particles containing meteoric material at low altitudes}

Figure 8 showed that particles containing meteoric material are transported downwards through stratospheretroposphere exchange and are therefore also present in the troposphere, albeit at low concentrations and low number fractions. We used two datasets from lower altitudes to estimate the occurrence of this particle type in the middle and lower troposphere. These are the abovementioned NETCARE dataset (Canadian Arctic in summer 2014) that contains aircraft-based ALABAMA data up to $3 \mathrm{~km}$ altitude (Köllner et al., 2017) and a mountaintop dataset from the Jungfraujoch station at $3600 \mathrm{~m}$ altitude in winter 2017. In both datasets the relative number of meteoric particles was 
(a)

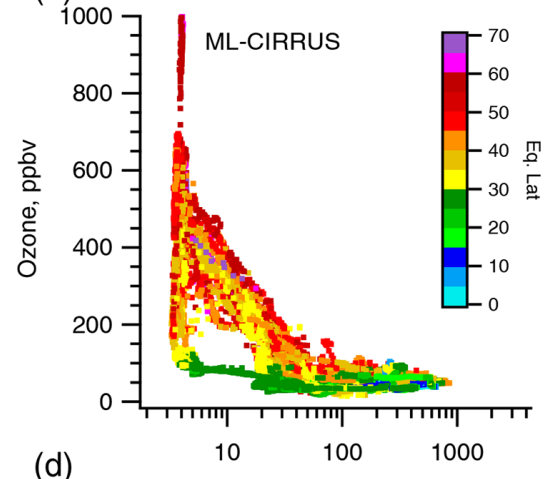

(d)
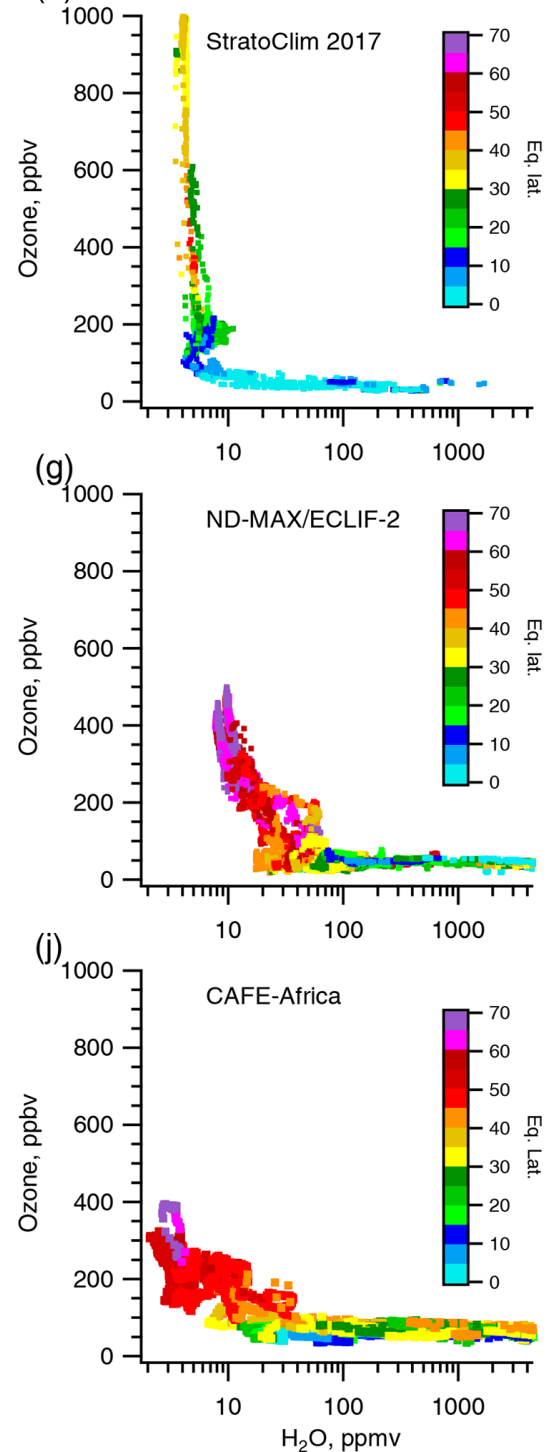

(b)

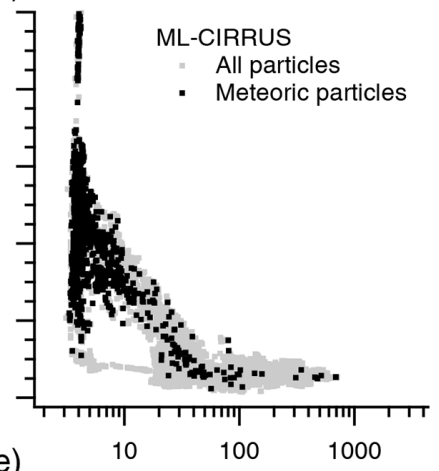

(e)

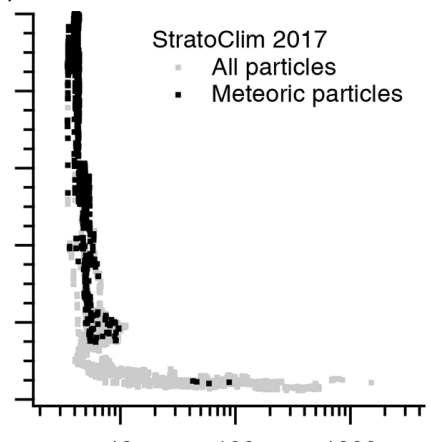

(h)

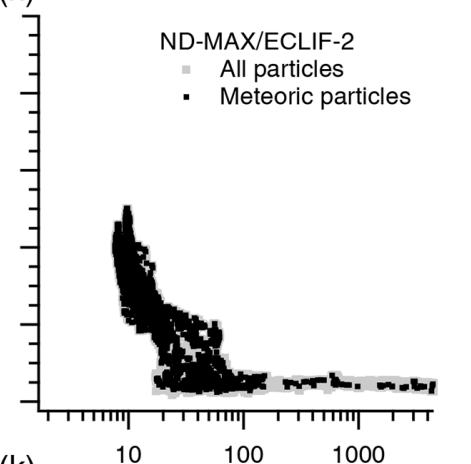

(k)

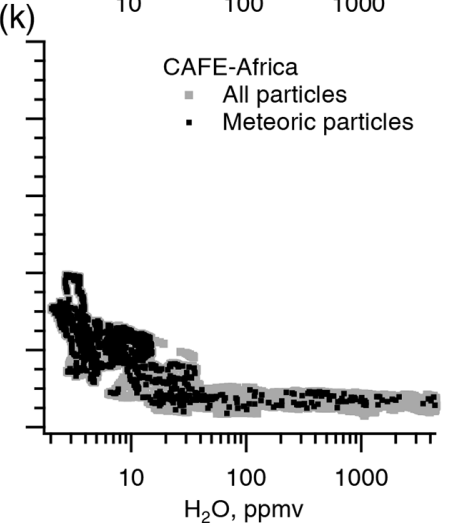

(c)

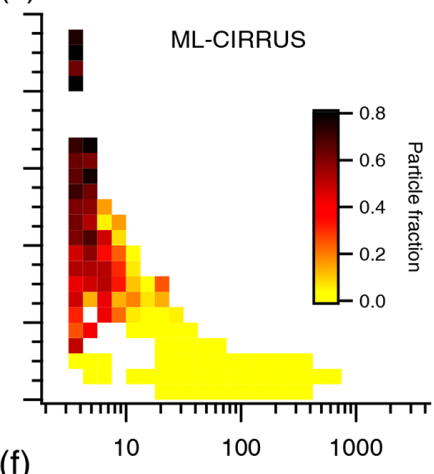

(f)

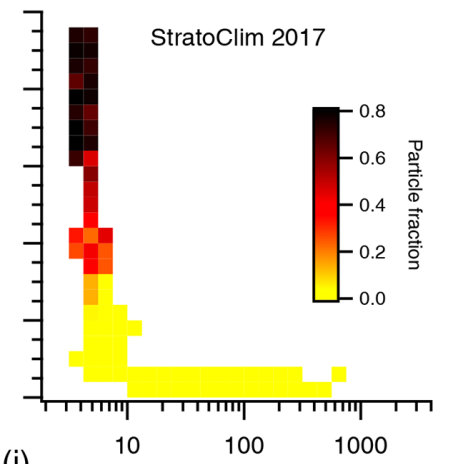

(i)

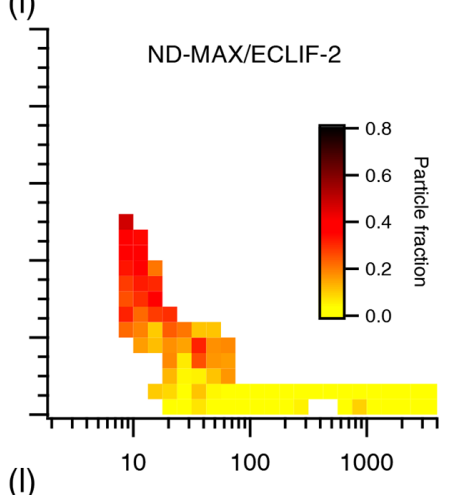

(I)



Figure 8. Ozone mixing ratio as stratospheric tracer vs. water vapour mixing ratio as tropospheric tracer colour-coded with equivalent latitude, for ML-CIRRUS (a), StratoClim 2017 (d), ND-MAX/ECLIF-2 (g), and CAFE-Africa (j). Panels (b), (e), (h), and (k) show O 3 and $\mathrm{H}_{2} \mathrm{O}$ for the times when particle mass spectra were recorded (grey for all particles and black for meteoric particles). Panels (c), (f), (i), and (l) show the proportion of meteoric particles within a $\mathrm{O}_{3}-\mathrm{H}_{2} \mathrm{O}$ grid. 
very low $(0.0025 \%-1 \%)$ such that an automated cluster algorithm would not find this particle type unless the prescribed number of clusters would be set to a very high value. Thus, we used the most prominent mass spectral features from this particle type as observed in the stratosphere (Fig. 2) and scanned the two low-altitude datasets for these marker peaks. The criteria included the presence of ${ }^{24} \mathrm{Mg},{ }^{25} \mathrm{Mg}$, ${ }^{26} \mathrm{Mg},{ }^{54} \mathrm{Fe}$, and ${ }^{56} \mathrm{Fe}$; the absence of $\mathrm{Cl}$ (to exclude sea spray); and a signal intensity of $m / z 39$ smaller than that of $m / z 41$. The latter was introduced to minimize the influence of potassium from other sources, especially dust. By varying these search criteria, different numbers of mass spectra with similar average mass spectra were obtained such that the absolute number of meteoric particles at low altitude is highly uncertain. Figure 9 shows the averaged mass spectra matching the criteria given above. The spectra correspond very well to the spectra sampled in the stratosphere (Fig. 2). A higher contribution of $m / z 18\left(\mathrm{NH}_{4}^{+}\right)$, especially in the Jungfraujoch spectra indicates a higher degree of neutralization of the sulfuric acid by ammonia in the troposphere than in the stratosphere. During NETCARE, 6 out of about 10000 particle mass spectra matched the criteria. By changing the criterion for potassium to an absolute upper intensity threshold, the number of spectra was reduced to three. Thus, the fraction of meteoric particles found in the summer Arctic lower troposphere can be estimated to be around $0.025 \%-$ $0.05 \%$. In the free-tropospheric dataset obtained in winter at Jungfraujoch, about 4100 spectra (out of more than 765 000) matched the criteria, corresponding to $0.5 \%$. Also here, by varying the criteria the percentage varies between $0.2 \%$ and $1 \%$. This range is clearly larger than that in the Arctic summer, but it has to be kept in mind that the Jungfraujoch dataset was obtained at $3600 \mathrm{~m}$ altitude, whereas the measurements during NETCARE only reached up to $3000 \mathrm{~m}$. In winter the Jungfraujoch station is mainly located in the free troposphere (over $60 \%$ of the time; see Bukowiecki et al., 2016) such that the influence of boundary layer particles is low. In contrast, the aerosol particles in the summer Arctic during NETCARE were to a large degree influenced by particles from marine biogenic origin (Köllner et al., 2017). Back-trajectory calculations for the Jungfraujoch dataset showed that the fraction of detected meteoric particles was higher during times when the air masses experienced higher altitudes and higher latitudes during the $5 \mathrm{~d}$ before the measurements (Sect. 8 and Fig. S11 in the Supplement). Additionally, the fraction of meteoric particles followed the time trend of the ozone mixing ratio (Fig. S11), confirming the stratospheric origin. Overall, this shows that the meteoric material immersed in stratospheric sulfuric acid aerosol particles reaches the lower troposphere from where it will be removed by wet removal (rain-out or wash-out), thereby finally reaching Earth's surface. This is confirmed by a number of studies that reported the detection of meteoric material in ice cores samples from Greenland (Gabrielli et al., 2004; Lanci et al., 2012) and Antarctica (Gabrielli et al., 2006).

\section{Discussion and conclusion}

In this study we present stratospheric single-particle mass spectrometer data from five aircraft-based campaigns, covering a wide range of Northern Hemisphere latitudes (15$68^{\circ} \mathrm{N}$ ) and seasons (winter, spring, and summer). In all datasets a distinct particle type characterized by iron and magnesium was observed in the stratosphere. The observed distribution as a function of potential temperature and potential vorticity suggests that the source of this particle type is above the tropopause. Consistent with previous stratospheric aerosol composition measurement data (Mossop, 1965; Murphy et al., 1998, 2014; Cziczo et al., 2001), meteoric composition data (Lodders and Fegley Jr., 1998; Rapp et al., 2012; Plane et al., 2015), and theory of meteoric ablation and fragmentation (Plane, 2003; Carrillo-Sánchez et al., 2016; Subasinghe et al., 2016), it is concluded that this particle type represents meteoric material partially dissolved within sulfuric acid solution droplets.

Downward transport of meteoric smoke particles from the mesosphere into the lowermost stratosphere occurs efficiently in the polar vortex (Curtius et al., 2005; Weigel et al., 2014). These papers show that high-altitude aircraft measurements demonstrate there is a higher proportion of refractory particles $(60 \%-70 \%)$ within the wintertime polar vortex, and one would therefore expect to find a higher abundance of meteoric particles in the lower stratosphere at high latitudes during late winter and early spring than at lower extratropical latitudes and than in other seasons. This expectation would largely agree with (1) the results by Dhomse et al. (2013), who predicted a more effective (by a factor of $\sim 15$ ) deposition of meteoric ablation material over Greenland than in Antarctica, and (2) the works of Bardeen et al. (2008) and Brooke et al. (2017), according to which the meteoric ablation material most effectively subsides to stratospheric altitudes within the polar winter vortex. This is not confirmed by our observations: although two mid-latitude campaigns (MLCIRRUS and ND-MAX/ECLIF-2) were conducted between January and April, we observe the same fraction of meteoric particles at the same ozone levels in the lower stratosphere (Fig. 3) during all campaigns, regardless of latitude and season.

Satellite observations with the CALIOP (Cloud-Aerosol Lidar and Infrared Pathfinder Satellite Observation) lidar instrument have shown that the lower edge of the stratospheric aerosol layer lies between 450 and $500 \mathrm{~K}$ potential temperature for latitudes between 20 and $50^{\circ} \mathrm{N}$ (Vernier et al., 2009). It is important to note, however, that Aitken-sized particles (a few tens of nanometres; e.g. Cadle and Kiang, 1977) are present throughout the upper troposphere and lower stratosphere, with this altitude range from the CALIOP measurements referring only to the optically interacting aerosol population. Thus, we conclude that the particles containing meteoric material that we observed in the lower stratosphere (with diameters greater than $200 \mathrm{~nm}$ ) originate from the strato- 

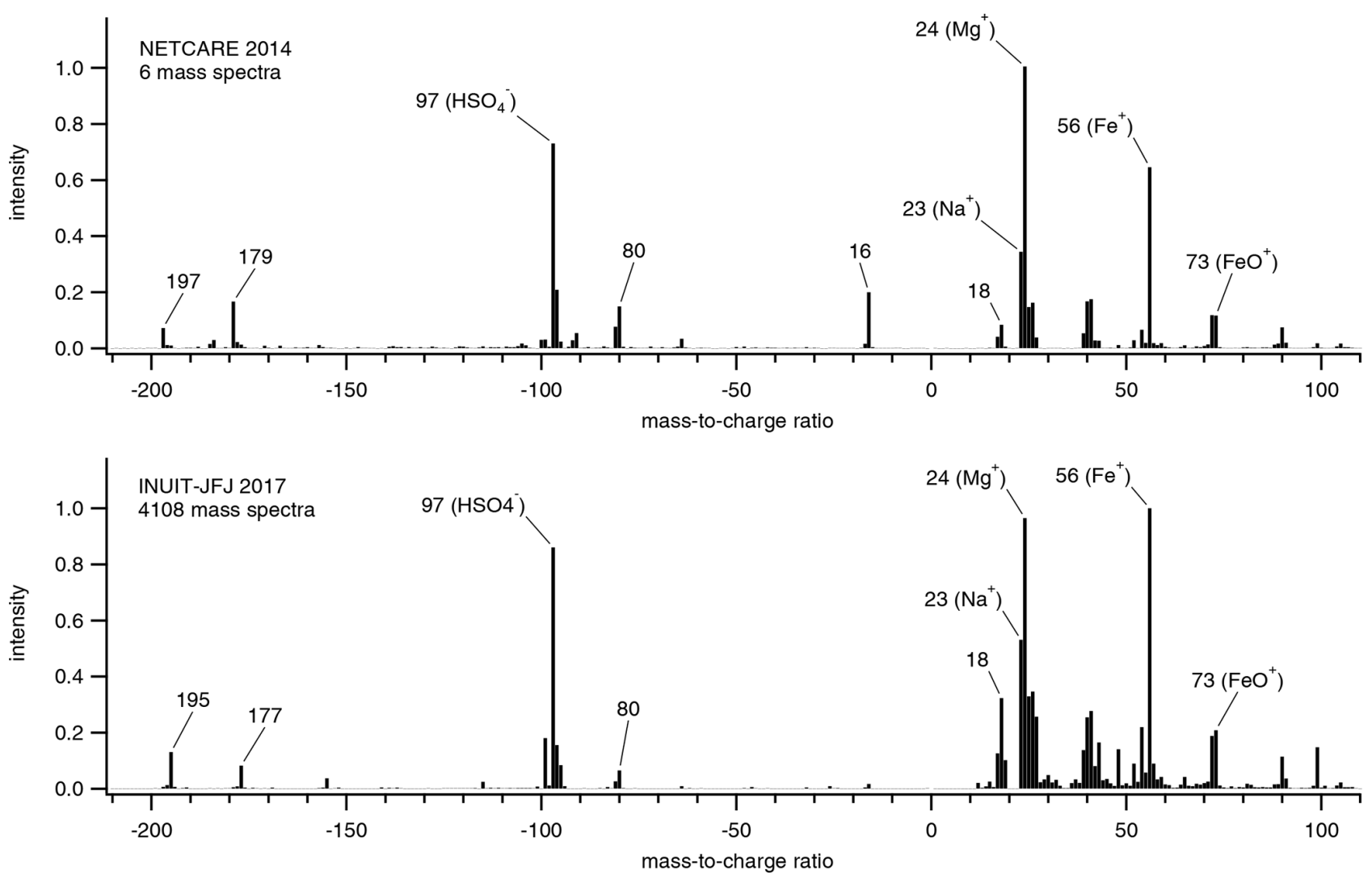

Figure 9. Mass spectra from low altitudes (NETCARE in the Canadian Arctic in summer 2014 at up to 3 km; Jungfraujoch, Switzerland, in winter 2017 at $3600 \mathrm{~m}$ ) showing meteoric signatures.

spheric aerosol layer. Our measurements between 20 and $40^{\circ} \mathrm{N}$ reach up to the lower edge of the stratospheric aerosol layer (see Fig. 4), whereas at higher latitudes and lower altitudes we assume that we observed particles that settled gravitationally from the stratospheric aerosol layer. This in turn means that the particles of the stratospheric aerosol layer contain meteoric material at all latitudes. We therefore conclude that meteoric material is indeed carried within the winter polar vortex from the mesosphere to the stratosphere but that isentropic mixing above $440 \mathrm{~K}$ potential temperature (see Fig. 4) distributes the meteoric material over all latitudes. Isentropic mixing in the stratosphere not only within the extratropics but also between the tropics and extratropics has been described previously (Neu and Plumb, 1999; Garny et al., 2014). From our data we can infer that at the lower edge of the stratospheric aerosol layer (above $440 \mathrm{~K}$ potential temperature) the meteoric material is equally distributed throughout the latitude range of about 20 to $60^{\circ} \mathrm{N}$. Our observations of particles with signatures of meteoric material do not clearly indicate the formation history, i.e. whether the material originates from meteoric disintegration by ablation (MSP), by fragmentation (MF), or from interplanetary dust particles (IDPs), since the material is at least partially dissolved in sulfuric acid.
We calculated the terminal settling velocity for particles of different sizes and densities (pure $\mathrm{H}_{2} \mathrm{SO}_{4}$ at $\rho=1.83 \mathrm{~g} \mathrm{~cm}^{-3}$ and pure olivine as a surrogate for meteoric composition at $\rho=3.30 \mathrm{~g} \mathrm{~cm}^{-3}$ ) as a function of altitude (for details see Sect. S5 in the Supplement). Between 16 and $18 \mathrm{~km}$, the settling velocity ranges between 1 and $12 \mathrm{~m} \mathrm{~d}^{-1}$ for particles between 100 and $500 \mathrm{~nm}$ having the densities given above. In the AMA, air masses are transported upwards between about 360 and $460 \mathrm{~K}$ with about $1.5 \mathrm{~K} \mathrm{~d}^{-1}$ (Ploeger et al., 2017; Vogel et al., 2019), corresponding to about $35-40 \mathrm{md}^{-1}$. This is larger than the above-calculated range; thus sedimentation is not fast enough to overcome the Asian monsoon upward motion. This explains why in the tropics we observe the increased fraction of particles containing meteoric material only $30 \mathrm{~K}$ above the thermal tropopause (see Fig. 4), whereas in the extratropics, where little upward motion occurs, we see these particles directly above the tropopause.

Our data further show that all meteoric particles contained $\mathrm{H}_{2} \mathrm{SO}_{4}$ but no other anions like nitrate or organic material. Thus, from our simultaneous cation and anion measurements we can confirm previous assumptions that $\mathrm{Mg}$ and $\mathrm{Fe}$ are dissolved in $\mathrm{H}_{2} \mathrm{SO}_{4}$ (Murphy et al., 1998, 2014; Cziczo et al., 2001). This suggests that these particles act similar to pure $\mathrm{H}_{2} \mathrm{SO}_{4}$ droplets in the UT with respect to cirrus formation, 
but it is conceivable that dissolved meteoric material alters the viscosity of $\mathrm{H}_{2} \mathrm{SO}_{4}-\mathrm{H}_{2} \mathrm{O}$ droplets, which was found to increase at low temperatures (Williams and Long, 1995). With respect to PSC formation in the polar stratosphere, the works by James et al. (2018) and Tritscher et al. (2019) showed that "foreign nuclei" are needed to be included in their simulations to reproduce PSC observations. The finding that meteoric material is mainly present as a dilute solution in $\mathrm{H}_{2} \mathrm{SO}_{4}-\mathrm{H}_{2} \mathrm{O}$ droplets needs to be included in future simulations.

In general, the meteoric particle type represents a good tracer for stratospheric aerosol particles. Downward transport along mixing lines at mid latitudes was clearly identified but only for equivalent latitudes above $30^{\circ} \mathrm{N}$. In datasets acquired in the lower troposphere the meteoric compositionsignature particles were detected as well, albeit only in very minor fractional abundance. Their size and composition (larger than $200 \mathrm{~nm}$, composed mainly of $\mathrm{H}_{2} \mathrm{SO}_{4}$, and most likely neutralized by ammonia in the troposphere) makes them ideal $\mathrm{CCN}$ (cloud condensation nuclei) such that they will be efficiently removed from the atmosphere by nucleation scavenging and wet removal, with the meteoric material being transported by these processes to Earth's surface. We reiterate that our findings of relatively invariant meteoric particle fraction are for particles larger than $200 \mathrm{~nm}$. The data from the Arctic campaigns (Curtius et al., 2005; Weigel et al., 2014) are for particles larger than $10 \mathrm{~nm}$, including also stratospheric Aitken-sized particles, which will have a different abundance fraction of particles containing meteoric material. The analysis presented here, combining data obtained with two different laser ablation mass spectrometers during five aircraft missions conducted at different seasons, latitudes, and altitudes, as well as two low-altitude datasets, has confirmed the widespread occurrence of meteoric material in stratospheric aerosol particles. Using the particles containing meteoric material as a tracer for stratospheric transport, our observations confirm the upward motion of air masses over the Asian monsoon anticyclone and the associated transport into the stratosphere, the exchange between the stratosphere and troposphere in the extratropics, and the efficient isentropic mixing between high and low latitudes above $440 \mathrm{~K}$ potential temperature.

Data availability. The data shown in this study are available at Edmond - the Open Access Data Repository of the Max Planck Society, under the following permanent link: https://doi.org/10.17617/3.38 (Schneider, 2019).

Supplement. The supplement related to this article is available online at: https://doi.org/10.5194/acp-21-989-2021-supplement.
Author contributions. JS evaluated the data, compiled the figures, and drafted the paper with contributions by RW. PHOO contributed significantly to the discussion on cross-tropopause mixing. Single-particle mass spectrometer data were provided by OA, AH, AD, SM, and SB (ERICA) and JS, TK, FK, OE, and HCC (ALABAMA). JUG provided meteorological reanalyses. CM provided UHSAS data. AZ, FO, HS, MS, FR, and AU provided ozone data. MK, CR, MZ, GSD, JPD, and JBN provided water vapour data. PHOP provided information on meteoric composition. The paper was critically reviewed by RW, SB, OA, FK, HCC, AH, OE, PHOP, PHOO, MK, CR, and JUG.

Competing interests. The authors declare that they have no conflict of interest.

Special issue statement. This article is part of the special issue "StratoClim stratospheric and upper tropospheric processes for better climate predictions (ACP/AMT inter-journal SI)". It is not associated with a conference.

Acknowledgements. We acknowledge that the International Foundation High Altitude Research Stations Jungfraujoch and Gornergrat (HFSJG), 3012 Bern, Switzerland, made it possible for us to carry out our experiment at the High Altitude Research Station at Jungfraujoch. The Swiss Federal Laboratories for Materials Science and Technology (EMPA) is acknowledged for providing ozone data for Jungfraujoch through the EBAS-EMEP database. We acknowledge the NOAA Air Resources Laboratory (ARL) for the provision of the HYSPLIT transport and dispersion model and/or READY website (http://www.ready.noaa.gov, last access: 18 January 2021) used in this publication. We thank the technical and scientific coordinators of the aircraft campaigns: Christiane Voigt, Andreas Minikin, Ulrich Schumann (ML-CIRRUS), Jos Lelieveld, Horst Fischer, Jonathan Williams, Marcel Dorf (CAFEAfrica), Bruce Anderson, Timothy Moes (NDMAX/ ECLIF-2), Fred Stroh, Markus Rex, Francesco Cairo (StratoClim), Andreas Herber, Jonathan Abbatt, and Richard Leaitch (NETCARE). We also thank all aircraft crews, campaign teams, and hangar staff (especially the staff of 120 ATW (Air Training Wing) at Kalamata), as well as the technical staff at MPIC for support during instrument development and operation during field campaigns. We thank the reviewers for their detailed and helpful suggestions to improve the paper.

Financial support. This work was funded by the DFG as a Priority Programme (SPP 1294, grant no. SCHN1138/1-2, ML-CIRRUS) and by the European Research Council (ERC) for EU FP7 2007-2013 (project no. 603557 for StratoClim and no. 321040 for EXCATRO). StratoClim was also supported by the BMBF under the joint ROMIC project SPITFIRE (no. 01LG1205A). CAFE-Africa was funded by the Max Planck Society. ND-MAX was funded by the NASA Advanced Air Vehicles Program (programme manager Jay Dryer). Funding for NETCARE was provided by the Natural Sciences and Engineering Research Council of Canada through the NETCARE project of the Climate Change 
and Atmospheric Research programme. The measurements at Jungfraujoch were funded by the DFG (grant no. SCHN1138/2-2, FOR1525 "INUIT") and by the EU Horizon 2020 research and innovation programme (grant no. 654109, ACTRIS-2).

The article processing charges for this open-access publication were covered by the Max Planck Society.

Review statement. This paper was edited by Rob MacKenzie and reviewed by two anonymous referees.

\section{References}

Abbatt, J. P. D., Leaitch, W. R., Aliabadi, A. A., Bertram, A. K., Blanchet, J.-P., Boivin-Rioux, A., Bozem, H., Burkart, J., Chang, R. Y. W., Charette, J., Chaubey, J. P., Christensen, R. J., Cirisan, A., Collins, D. B., Croft, B., Dionne, J., Evans, G. J., Fletcher, C. G., Galí, M., Ghahremaninezhad, R., Girard, E., Gong, W., Gosselin, M., Gourdal, M., Hanna, S. J., Hayashida, H., Herber, A. B., Hesaraki, S., Hoor, P., Huang, L., Hussherr, R., Irish, V. E., Keita, S. A., Kodros, J. K., Köllner, F., Kolonjari, F., Kunkel, D., Ladino, L. A., Law, K., Levasseur, M., Libois, Q., Liggio, J., Lizotte, M., Macdonald, K. M., Mahmood, R., Martin, R. V., Mason, R. H., Miller, L. A., Moravek, A., Mortenson, E., Mungall, E. L., Murphy, J. G., Namazi, M., Norman, A.-L., O’Neill, N. T., Pierce, J. R., Russell, L. M., Schneider, J., Schulz, H., Sharma, S., Si, M., Staebler, R. M., Steiner, N. S., Thomas, J. L., von Salzen, K., Wentzell, J. J. B., Willis, M. D., Wentworth, G. R., Xu, J.W., and Yakobi-Hancock, J. D.: Overview paper: New insights into aerosol and climate in the Arctic, Atmos. Chem. Phys., 19, 2527-2560, https://doi.org/10.5194/acp-19-2527-2019, 2019.

Afchine, A., Rolf, C., Costa, A., Spelten, N., Riese, M., Buchholz, B., Ebert, V., Heller, R., Kaufmann, S., Minikin, A., Voigt, C., Zöger, M., Smith, J., Lawson, P., Lykov, A., Khaykin, S., and Krämer, M.: Ice particle sampling from aircraft - influence of the probing position on the ice water content, Atmos. Meas. Tech., 11, 4015-4031, https://doi.org/10.5194/amt11-4015-2018, 2018.

Alpers, M., Gerding, M., Höffner, J., and Schneider, J.: Multiwavelength lidar observation of a strange noctilucent cloud at Kühlungsborn, Germany ( $\left.54^{\circ} \mathrm{N}\right)$, J. Geophys. Res.-Atmos., 106, 7945-7953, https://doi.org/10.1029/2000JD900666, 2001.

Andersson, S. M., Martinsson, B. G., Friberg, J., Brenninkmeijer, C. A. M., Rauthe-Schöch, A., Hermann, M., van Velthoven, P. F. J., and Zahn, A.: Composition and evolution of volcanic aerosol from eruptions of Kasatochi, Sarychev and Eyjafjallajökull in 2008-2010 based on CARIBIC observations, Atmos. Chem. Phys., 13, 1781-1796, https://doi.org/10.5194/acp13-1781-2013, 2013.

Andreae, M. O., Afchine, A., Albrecht, R., Holanda, B. A., Artaxo, P., Barbosa, H. M. J., Borrmann, S., Cecchini, M. A., Costa, A., Dollner, M., Fütterer, D., Järvinen, E., Jurkat, T., Klimach, T., Konemann, T., Knote, C., Krämer, M., Krisna, T., Machado, L. A. T., Mertes, S., Minikin, A., Pöhlker, C., Pöhlker, M. L., Pöschl, U., Rosenfeld, D., Sauer, D., Schlager, H., Schnaiter, M., Schneider, J., Schulz, C., Spanu, A., Sperling, V. B., Voigt, C., Walser, A., Wang, J., Weinzierl, B., Wendisch, M., and Ziereis,
H.: Aerosol characteristics and particle production in the upper troposphere over the Amazon Basin, Atmos. Chem. Phys., 18, 921-961, https://doi.org/10.5194/acp-18-921-2018, 2018.

Arnold, F., Curtius, J., Spreng, S., and Deshler, T.: Stratospheric aerosol sulfuric acid: First direct in situ measurements using a novel balloon-based mass spectrometer apparatus, J. Atmos. Chem., 30, 3-10, https://doi.org/10.1023/a:1006067511568, 1998.

Bardeen, C. G., Toon, O. B., Jensen, E. J., Marsh, D. R., and Harvey, V. L.: Numerical simulations of the threedimensional distribution of meteoric dust in the mesosphere and upper stratosphere, J. Geophys. Res.-Atmos., 113, D17202, https://doi.org/10.1029/2007jd009515, 2008.

Bezdek, J. C., Ehrlich, R., and Full, W.: FCM: The fuzzy cmeans clustering algorithm, Comput. Geosci., 10, 191-203, https://doi.org/10.1016/0098-3004(84)90020-7, 1984.

Brands, M., Kamphus, M., Böttger, T., Schneider, J., Drewnick, F., Roth, A., Curtius, J., Voigt, C., Borbon, A., Beekmann, M., Bourdon, A., Perrin, T., and Borrmann, S.: Characterization of a Newly Developed Aircraft-Based Laser Ablation Aerosol Mass Spectrometer (ALABAMA) and First Field Deployment in Urban Pollution Plumes over Paris During MEGAPOLI 2009, Aerosol Sci. Tech., 45, 46-64, https://doi.org/10.1080/02786826.2010.517813, 2011.

Brooke, J. S. A., Feng, W., Carrillo-Sánchez, J. D., Mann, G. W., James, A. D., Bardeen, C. G., Marshall, L., Dhomse, S. S., and Plane, J. M. C.: Meteoric Smoke Deposition in the Polar Regions: A Comparison of Measurements With Global Atmospheric Models, J. Geophys. Res.-Atmos., 122, 11112-11130, https://doi.org/10.1002/2017JD027143, 2017.

Bukowiecki, N., Weingartner, E., Gysel, M., Coen, M. C., Zieger, P., Herrmann, E., Steinbacher, M., Gäggeler, H. W., and Baltensperger, U.: A Review of More than 20 Years of Aerosol Observation at the High Altitude Research Station Jungfraujoch, Switzerland (3580 m asl), Aerosol Air Qual. Res., 16, 764-788, https://doi.org/10.4209/aaqr.2015.05.0305, 2016.

Burkholder, J. B., Mills, M., and McKeen, S.: Upper limit for the UV absorption cross sections of $\mathrm{H}_{2} \mathrm{SO}_{4}$, Geophys. Res. Lett., 27, 2493-2496, https://doi.org/10.1029/1999GL011271, 2000.

Cadle, R. D. and Kiang, C. S.: Stratospheric Aitken particles, Rev. Geophys., 15, 195-202, https://doi.org/10.1029/RG015i002p00195, 1977.

Carrillo-Sánchez, J. D., Nesvorný, D., Pokorný, P., Janches, D., and Plane, J. M. C.: Sources of cosmic dust in the Earth's atmosphere, Geophys. Res. Lett., 43, 11979-11986, https://doi.org/10.1002/2016GL071697, 2016.

Clemen, H.-C., Schneider, J., Klimach, T., Helleis, F., Köllner, F., Hünig, A., Rubach, F., Mertes, S., Wex, H., Stratmann, F., Welti, A., Kohl, R., Frank, F., and Borrmann, S.: Optimizing the detection, ablation, and ion extraction efficiency of a single-particle laser ablation mass spectrometer for application in environments with low aerosol particle concentrations, Atmos. Meas. Tech., 13, 5923-5953, https://doi.org/10.5194/amt-13-5923-2020, 2020.

Curtius, J., Weigel, R., Vössing, H.-J., Wernli, H., Werner, A., Volk, C.-M., Konopka, P., Krebsbach, M., Schiller, C., Roiger, A., Schlager, H., Dreiling, V., and Borrmann, S.: Observations of meteoric material and implications for aerosol nucleation in the winter Arctic lower stratosphere derived from in 
situ particle measurements, Atmos. Chem. Phys., 5, 3053-3069, https://doi.org/10.5194/acp-5-3053-2005, 2005.

Cziczo, D. J., Thomson, D. S., and Murphy, D. M.: Ablation, flux, and atmospheric implications of meteors inferred from stratospheric aerosol, Science, 291, 1772-1775, https://doi.org/10.1126/science.1057737, 2001.

Cziczo, D. J., Murphy, D. M., Thomson, D. S., and Ross, M. N.: Composition of individual particles in the wakes of an Athena II rocket and the space shuttle, Geophys. Res. Lett., 29, 33-31-3334, https://doi.org/10.1029/2002GL015991, 2002.

Cziczo, D. J., Murphy, D. M., Hudson, P. K., and Thomson, D. S.: Single particle measurements of the chemical composition of cirrus ice residue during CRYSTAL-FACE, J. Geophys. Res.Atmos., 109, D04201 https://doi.org/10.1029/2003jd004032, 2004.

DeCarlo, P. F., Slowik, J. G., Worsnop, D. R., Davidovits, P., and Jimenez, J. L.: Particle morphology and density characterization by combined mobility and aerodynamic diameter measurements. Part 1: Theory, Aerosol Sci. Tech., 38, 1185-1205, https://doi.org/10.1080/027868290903907, 2004.

Dee, D. P., Uppala, S. M., Simmons, A. J., Berrisford, P., Poli, P., Kobayashi, S., Andrae, U., Balmaseda, M. A., Balsamo, G., Bauer, P., Bechtold, P., Beljaars, A. C. M., van de Berg, L., Bidlot, J., Bormann, N., Delsol, C., Dragani, R., Fuentes, M., Geer, A. J., Haimberger, L., Healy, S. B., Hersbach, H., Holm, E. V., Isaksen, L., Kallberg, P., Kohler, M., Matricardi, M., McNally, A. P., Monge-Sanz, B. M., Morcrette, J. J., Park, B. K., Peubey, C., de Rosnay, P., Tavolato, C., Thepaut, J. N., and Vitart, F.: The ERA-Interim reanalysis: configuration and performance of the data assimilation system, Q. J. Roy. Meteor. Soc., 137, 553-597, https://doi.org/10.1002/qj.828, 2011.

Deshler, T., Hervig, M. E., Hofmann, D. J., Rosen, J. M., and Liley, J. B.: Thirty years of in situ stratospheric aerosol size distribution measurements from Laramie, Wyoming $\left(41^{\circ} \mathrm{N}\right)$, using balloon-borne instruments, J. Geophys. Res.-Atmos., 108, 4167, https://doi.org/10.1029/2002jd002514, 2003.

Dhomse, S. S., Saunders, R. W., Tian, W., Chipperfield, M. P., and Plane, J. M. C.: Plutonium-238 observations as a test of modeled transport and surface deposition of meteoric smoke particles, Geophys. Res. Lett., 40, 4454-4458, https://doi.org/10.1002/grl.50840, 2013.

Diskin, G. S., Podolske, J. R., Sachse, G. W., and Slate, T. A.: Openpath airborne tunable diode laser hygrometer, in: Diode Lasers and Applications in Atmospheric Sensing, edited by: Fried, A., Proceedings of the Society of Photo-Optical Instrumentation Engineers (SPIE), 2002.

Ebert, M., Weigel, R., Kandler, K., Günther, G., Molleker, S., Grooß, J.-U., Vogel, B., Weinbruch, S., and Borrmann, S.: Chemical analysis of refractory stratospheric aerosol particles collected within the arctic vortex and inside polar stratospheric clouds, Atmos. Chem. Phys., 16, 8405-8421, https://doi.org/10.5194/acp-16-8405-2016, 2016.

Eriksen Hammer, S., Mertes, S., Schneider, J., Ebert, M., Kandler, K., and Weinbruch, S.: Composition of ice particle residuals in mixed-phase clouds at Jungfraujoch (Switzerland): enrichment and depletion of particle groups relative to total aerosol, Atmos. Chem. Phys., 18, 13987-14003, https://doi.org/10.5194/acp-1813987-2018, 2018.
Fischer, H., Wienhold, F. G., Hoor, P., Bujok, O., Schiller, C., Siegmund, P., Ambaum, M., Scheeren, H. A., and Lelieveld, J.: Tracer correlations in the northern high latitude lowermost stratosphere: Influence of cross-tropopause mass exchange, Geophys. Res. Lett., 27, 97-100, https://doi.org/10.1029/1999g1010879, 2000.

Froyd, K. D., Murphy, D. M., Sanford, T. J., Thomson, D. S., Wilson, J. C., Pfister, L., and Lait, L.: Aerosol composition of the tropical upper troposphere, Atmos. Chem. Phys., 9, 4363-4385, https://doi.org/10.5194/acp-9-4363-2009, 2009.

Froyd, K. D., Murphy, D. M., Brock, C. A., Campuzano-Jost, P., Dibb, J. E., Jimenez, J.-L., Kupc, A., Middlebrook, A. M., Schill, G. P., Thornhill, K. L., Williamson, C. J., Wilson, J. C., and Ziemba, L. D.: A new method to quantify mineral dust and other aerosol species from aircraft platforms using singleparticle mass spectrometry, Atmos. Meas. Tech., 12, 6209-6239, https://doi.org/10.5194/amt-12-6209-2019, 2019.

Fueglistaler, S., Dessler, A. E., Dunkerton, T. J., Folkins, I., Fu, Q., and Mote, P. W.: Tropical tropopause layer, Rev. Geophys., 47, RG1004, https://doi.org/10.1029/2008rg000267, 2009.

Gabrielli, P., Barbante, C., Plane, J. M. C., Varga, A., Hong, S., Cozzi, G., Gaspari, V., Planchon, F. A. M., Cairns, W., Ferrari, C., Crutzen, P., Cescon, P., and Boutron, C. F.: Meteoric smoke fallout over the Holocene epoch revealed by iridium and platinum in Greenland ice, Nature, 432, 1011-1014, https://doi.org/10.1038/nature03137, 2004.

Gabrielli, P., Plane, J. M. C., Boutron, C. F., Hong, S. M., Cozzi, G., Cescon, P., Ferrari, C., Crutzen, P. J., Petit, J. R., Lipenkov, V. Y., and Barbante, C.: A climatic control on the accretion of meteoric and super-chondritic iridium-platinum to the Antarctic ice cap, Earth Planet. Sc. Lett., 250, 459-469, https://doi.org/10.1016/j.epsl.2006.08.015, 2006.

Gallavardin, S., Lohmann, U., and Cziczo, D.: Analysis and differentiation of mineral dust by single particle laser mass spectrometry, Int. J. Mass Spectrom., 274, 56-63, https://doi.org/10.1016/j.ijms.2008.04.031, 2008.

Gandrud, B. W., Sperry, P. D., Sanford, L., Kelly, K. K., Ferry, G. V., and Chan, K. R.: Filter measurement results from the airborne Antarctic ozone experiment, J. Geophys. Res.-Atmos., 94, 11285-11297, https://doi.org/10.1029/JD094iD09p11285, 1989.

Garny, H., Birner, T., Bönisch, H., and Bunzel, F.: The effects of mixing on age of air, J. Geophys. Res.-Atmos., 119, 7015-7034, https://doi.org/10.1002/2013JD021417, 2014.

Gettelman, A., Hoor, P., Pan, L. L., Randel, W. J., Hegglin, M. I., and Birner, T.: The extratropical upper troposphere and lower stratosphere, Rev. Geophys., 49, RG3003, https://doi.org/10.1029/2011RG000355, 2011.

Gettelman, A., Liu, X., Barahona, D., Lohmann, U., and Chen, C.: Climate impacts of ice nucleation, J. Geophys. Res.-Atmos., 117, D20201, https://doi.org/10.1029/2012JD017950, 2012.

Grooß, J.-U., Engel, I., Borrmann, S., Frey, W., Günther, G., Hoyle, C. R., Kivi, R., Luo, B. P., Molleker, S., Peter, T., Pitts, M. C., Schlager, H., Stiller, G., Vömel, H., Walker, K. A., and Müller, R.: Nitric acid trihydrate nucleation and denitrification in the Arctic stratosphere, Atmos. Chem. Phys., 14, 1055-1073, https://doi.org/10.5194/acp-14-1055-2014, 2014.

Gumbel, J. and Megner, L.: Charged meteoric smoke as ice nuclei in the mesosphere: Part $1-\mathrm{A}$ review of ba- 
sic concepts, J. Atmos. Sol.-Terr. Phys., 71, 1225-1235, https://doi.org/10.1016/j.jastp.2009.04.012, 2009.

Gunsch, M. J., May, N. W., Wen, M., Bottenus, C. L. H., Gardner, D. J., VanReken, T. M., Bertman, S. B., Hopke, P. K., Ault, A. P., and Pratt, K. A.: Ubiquitous influence of wildfire emissions and secondary organic aerosol on summertime atmospheric aerosol in the forested Great Lakes region, Atmos. Chem. Phys., 18, 3701-3715, https://doi.org/10.5194/acp-18-3701-2018, 2018.

Gute, E., Lacher, L., Kanji, Z. A., Kohl, R., Curtius, J., Weber, D., Bingemer, H., Clemen, H.-C., Schneider, J., GyselBeer, M., Ferguson, S. T., and Abbatt, J. P. D.: Field evaluation of a Portable Fine Particle Concentrator (PFPC) for ice nucleating particle measurements, Aerosol Sci. Tech., 1-12, https://doi.org/10.1080/02786826.2019.1626346, 2019.

Hegglin, M. I., Brunner, D., Peter, T., Hoor, P., Fischer, H., Staehelin, J., Krebsbach, M., Schiller, C., Parchatka, U., and Weers, U.: Measurements of $\mathrm{NO}, \mathrm{NO}_{y}, \mathrm{~N}_{2} \mathrm{O}$, and $\mathrm{O}_{3}$ during SPURT: implications for transport and chemistry in the lowermost stratosphere, Atmos. Chem. Phys., 6, 1331-1350, https://doi.org/10.5194/acp6-1331-2006, 2006.

Heller, R., Voigt, C., Beaton, S., Dörnbrack, A., Giez, A., Kaufmann, S., Mallaun, C., Schlager, H., Wagner, J., Young, K., and Rapp, M.: Mountain waves modulate the water vapor distribution in the UTLS, Atmos. Chem. Phys., 17, 14853-14869, https://doi.org/10.5194/acp-17-14853-2017, 2017.

Hemenway, C. L. and Soberman, R. K.: Symposium: Small meteoric particles in the earth's neighborhood: Studies of micrometeorites obtained from a recoverable sounding rocket, Astron. J., 67, 256, https://doi.org/10.1086/108705, 1962

Hervig, M. E., Deaver, L. E., Bardeen, C. G., Russell, J. M., Bailey, S. M., and Gordley, L. L.: The content and composition of meteoric smoke in mesospheric ice particles from SOFIE observations, J. Atmos. Sol.-Terr. Phys., 84-85, 1-6, https://doi.org/10.1016/j.jastp.2012.04.005, 2012.

Hervig, M. E., Brooke, J. S. A., Feng, W., Bardeen, C. G., and Plane, J. M. C.: Constraints on Meteoric Smoke Composition and Meteoric Influx Using SOFIE Observations With Models, J. Geophys. Res.-Atmos., 122, 13,495-413,505, https://doi.org/10.1002/2017JD027657, 2017.

Hicks, T. R., May, B. H., and Reay, N. K.: MgI emission in night-sky spectrum, Nature, 240, 401-402, https://doi.org/10.1038/240401a0, 1972.

Hinz, K. P., Greweling, M., Drews, F., and Spengler, B.: Data processing in on-line laser mass spectrometry of inorganic, organic, or biological airborne particles, J. Am. Soc. Mass Spectrom., 10, 648-660, https://doi.org/10.1016/s1044-0305(99)00028-8, 1999.

Holton, J. R., Haynes, P. H., McIntyre, M. E., Douglass, A. R., Rood, R. B., and Pfister, L.: Stratosphere-troposphere exchange, Rev. Geophys., 33, 403-439, https://doi.org/10.1029/95rg02097, 1995.

Hoor, P., Fischer, H., Lange, L., Lelieveld, J., and Brunner, D.: Seasonal variations of a mixing layer in the lowermost stratosphere as identified by the $\mathrm{CO}-\mathrm{O}_{3}$ correlation from in situ measurements, J. Geophys. Res.-Atmos., 107, ACL 1-1-ACL 1-11, https://doi.org/10.1029/2000jd000289, 2002.

Hoor, P., Gurk, C., Brunner, D., Hegglin, M. I., Wernli, H., and Fischer, H.: Seasonality and extent of extratropical TST derived from in-situ CO measurements during SPURT, Atmos. Chem.
Phys., 4, 1427-1442, https://doi.org/10.5194/acp-4-1427-2004, 2004.

Hoor, P., Wernli, H., Hegglin, M. I., and Bönisch, H.: Transport timescales and tracer properties in the extratropical UTLS, Atmos. Chem. Phys., 10, 7929-7944, https://doi.org/10.5194/acp10-7929-2010, 2010.

Höpfner, M., Ungermann, J., Borrmann, S., Wagner, R., Spang, R., Riese, M., Stiller, G., Appel, O., Batenburg, A. M., Bucci, S., Cairo, F., Dragoneas, A., Friedl-Vallon, F., Hünig, A., Johansson, S., Krasauskas, L., Legras, B., Leisner, T., Mahnke, C., Möhler, O., Molleker, S., Müller, R., Neubert, T., Orphal, J., Preusse, P., Rex, M., Saathoff, H., Stroh, F., Weigel, R., and Wohltmann, I.: Ammonium nitrate particles formed in upper troposphere from ground ammonia sources during Asian monsoons, Nat. Geosci., 12, 608-612, https://doi.org/10.1038/s41561-019-0385-8, 2019.

Hoppe, P.: 4.3.3 Meteorites, in: Solar System, edited by: Trümper, J. E., Springer, Berlin, Heidelberg, 582-602, 2009.

Hoskins, B. J., McIntyre, M. E., and Robertson, A. W.: On the use and significance of isentropic potential vorticity maps, Q. J. Roy. Meteor. Soc., 111, 877-946, https://doi.org/10.1256/smsqj.47001, 1985.

Jacchia, L. G.: The Physical Theory of Meteors. VIII. Fragmentation as Cause of the Faintmeteor Anomaly, Astrophys. J., 121, 521, https://doi.org/10.1086/146012, 1955.

James, A. D., Brooke, J. S. A., Mangan, T. P., Whale, T. F., Plane, J. M. C., and Murray, B. J.: Nucleation of nitric acid hydrates in polar stratospheric clouds by meteoric material, Atmos. Chem. Phys., 18, 4519-4531, https://doi.org/10.5194/acp18-4519-2018, 2018.

Junge, C. E. and Manson, J. E.: Stratospheric aerosol studies, J. Geophys. Res., 66, 2163-2182, https://doi.org/10.1029/JZ066i007p02163, 1961.

Junge, C. E., Chagnon, C. W., and Manson, J. E.: A Worldwide Stratospheric Aerosol Layer, Science, 133, 1478-1479, https://doi.org/10.1126/science.133.3463.1478-a, 1961.

Köllner, F., Schneider, J., Willis, M. D., Klimach, T., Helleis, F., Bozem, H., Kunkel, D., Hoor, P., Burkart, J., Leaitch, W. R., Aliabadi, A. A., Abbatt, J. P. D., Herber, A. B., and Borrmann, S.: Particulate trimethylamine in the summertime Canadian high Arctic lower troposphere, Atmos. Chem. Phys., 17, 1374713766, https://doi.org/10.5194/acp-17-13747-2017, 2017.

Krause, J., Hoor, P., Engel, A., Plöger, F., Grooß, J.-U., Bönisch, H., Keber, T., Sinnhuber, B.-M., Woiwode, W., and Oelhaf, H.: Mixing and ageing in the polar lower stratosphere in winter 2015-2016, Atmos. Chem. Phys., 18, 6057-6073, https://doi.org/10.5194/acp-18-6057-2018, 2018.

Kremser, S., Thomason, L. W., von Hobe, M., Hermann, M., Deshler, T., Timmreck, C., Toohey, M., Stenke, A., Schwarz, J. P., Weigel, R., Fueglistaler, S., Prata, F. J., Vernier, J.-P., Schlager, H., Barnes, J. E., Antuña-Marrero, J.-C., Fairlie, D., Palm, M., Mahieu, E., Notholt, J., Rex, M., Bingen, C., Vanhellemont, F., Bourassa, A., Plane, J. M. C., Klocke, D., Carn, S. A., Clarisse, L., Trickl, T., Neely, R., James, A. D., Rieger, L., Wilson, J. C., and Meland, B.: Stratospheric aerosol-Observations, processes, and impact on climate, Rev. Geophys., 54, 278-335, https://doi.org/10.1002/2015RG000511, 2016.

Kunz, A., Konopka, P., Muller, R., and Pan, L. L.: Dynamical tropopause based on isentropic potential vor- 
ticity gradients, J. Geophys. Res.-Atmos., 116, D01110, https://doi.org/10.1029/2010jd014343, 2011.

Lanci, L., Delmonte, B., Kent, D. V., Maggi, V., Biscaye, P. E., and Petit, J. R.: Magnetization of polar ice: a measurement of terrestrial dust and extraterrestrial fallout, Quaternary Sci. Rev., 33, 20-31, https://doi.org/10.1016/j.quascirev.2011.11.023, 2012.

Lary, D. J., Chipperfield, M. P., Pyle, J. A., Norton, W. A., and Riishojgaard, L. P.: 3-dimensional tracer initialization and general diagnostics using equivalent PV latitude-potentialtemperature coordinates, Q. J. Roy. Meteor. Soc., 121, 187-210, https://doi.org/10.1002/qj.49712152109, 1995.

Lazrus, A. L., and Gandrud, B. W.: Stratospheric sulfate aerosol, J. Geophys. Res., 79, 3424-3431, https://doi.org/10.1029/JC079i024p03424, 1974.

Lazrus, A. L. and Gandrud, B. W.: Stratospheric sulfate at high-altitudes, Geophys. Res. Lett., 4, 521-522, https://doi.org/10.1029/GL004i011p00521, 1977.

Lazrus, A. L., Gandrud, B., and Cadle, R. D.: Chemical composition of air filtration samples of stratospheric sulfate layer, J. Geophys. Res., 76, 8083-8088, https://doi.org/10.1029/JC076i033p08083, 1971.

Lodders, K. and Fegley Jr., B.: The Planetary Scientist's Companion, Oxford University Press, New York, Oxford, 1998.

Mahnke, C.: Untersuchungen zu Wolkenbildung und Aerosolmikrophysik in der tropischen Troposphäre und UT/LS: Messtechnik und flugzeuggetragene in-situ Beobachtungen, $\mathrm{PhD}$ thesis, Johannes Gutenberg University, Mainz, Germany, 2018 (in German).

Marcy, T. P., Popp, P. J., Gao, R. S., Fahey, D. W., Ray, E. A., Richard, E. C., Thompson, T. L., Atlas, E. L., Loewenstein, M., Wofsy, S. C., Park, S., Weinstock, E. M., Swartz, W. H., and Mahoney, M. J.: Measurements of trace gases in the tropical tropopause layer, Atmos. Environ., 41, 7253-7261, https://doi.org/10.1016/j.atmosenv.2007.05.032, 2007.

Megner, L. and Gumbel, J.: Charged meteoric particles as ice nuclei in the mesosphere: Part 2: A feasibility study, J. Atmos. Sol.-Terr. Phys., 71, 1236-1244, https://doi.org/10.1016/j.jastp.2009.05.002, 2009.

Megner, L., Rapp, M., and Gumbel, J.: Distribution of meteoric smoke - sensitivity to microphysical properties and atmospheric conditions, Atmos. Chem. Phys., 6, 4415-4426, https://doi.org/10.5194/acp-6-4415-2006, 2006.

Megner, L., Siskind, D. E., Rapp, M., and Gumbel, J.: Global and temporal distribution of meteoric smoke: A two-dimensional simulation study, J. Geophys. Res.-Atmos., 113, D03202, https://doi.org/10.1029/2007JD009054, 2008.

Meyer, J., Rolf, C., Schiller, C., Rohs, S., Spelten, N., Afchine, A., Zöger, M., Sitnikov, N., Thornberry, T. D., Rollins, A. W., Bozóki, Z., Tátrai, D., Ebert, V., Kühnreich, B., Mackrodt, P., Möhler, O., Saathoff, H., Rosenlof, K. H., and Krämer, M.: Two decades of water vapor measurements with the FISH fluorescence hygrometer: a review, Atmos. Chem. Phys., 15, 85218538, https://doi.org/10.5194/acp-15-8521-2015, 2015.

Molleker, S., Helleis, F., Klimach, T., Appel, O., Clemen, H.C., Dragoneas, A., Gurk, C., Hünig, A., Köllner, F., Rubach, F., Schulz, C., Schneider, J., and Borrmann, S.: Application of an O-ring pinch device as a constant-pressure inlet (CPI) for airborne sampling, Atmos. Meas. Tech., 13, 3651-3660, https://doi.org/10.5194/amt-13-3651-2020, 2020.
Mossop, S. C.: Stratospheric particles at $20 \mathrm{~km}$ altitude, Geochim. Cosmochim. Ac., 29, 101-102, https://doi.org//10.1016/00167037(65)90017-7, 1965.

Murphy, D. M.: The design of single particle laser mass spectrometers, Mass Spectrom. Rev., 26, 150-165, https://doi.org/10.1002/mas.20113, 2007.

Murphy, D. M., Thomson, D. S., and Mahoney, T. M. J.: In situ measurements of organics, meteoritic material, mercury, and other elements in aerosols at 5 to 19 kilometers, Science, 282, 1664 1669, https://doi.org/10.1126/science.282.5394.1664, 1998.

Murphy, D. M., Cziczo, D. J., Hudson, P. K., and Thomson, D. S.: Carbonaceous material in aerosol particles in the lower stratosphere and tropopause region, J. Geophys. Res.-Atmos., 112, D04203, https://doi.org/10.1029/2006jd007297, 2007.

Murphy, D. M., Froyd, K. D., Schwarz, J. P., and Wilson, J. C.: Observations of the chemical composition of stratospheric aerosol particles, Q. J. Roy. Meteor. Soc., 140, 1269-1278, https://doi.org/10.1002/qj.2213, 2014.

Neu, J. L. and Plumb, R. A.: Age of air in a "leaky pipe" model of stratospheric transport, J. Geophys. Res.-Atmos., 104, 1924319255, https://doi.org/10.1029/1999JD900251, 1999.

Pan, L. L., Randel, W. J., Gary, B. L., Mahoney, M. J., and Hintsa, E. J.: Definitions and sharpness of the extratropical tropopause: A trace gas perspective, J. Geophys. Res.-Atmos., 109, D23103, https://doi.org/10.1029/2004jd004982, 2004.

Pan, L. L., Paulik, L. C., Honomichl, S. B., Munchak, L. A., Bian, J. C., Selkirk, H. B., and Vomel, H.: Identification of the tropical tropopause transition layer using the ozone-water vapor relationship, J. Geophys. Res.-Atmos., 119, 3586-3599, https://doi.org/10.1002/2013jd020558, 2014.

Pan, L. L., Honomichl, S. B., Kinnison, D. E., Abalos, M., Randel, W. J., Bergman, J. W., and Bian, J.: Transport of chemical tracers from the boundary layer to stratosphere associated with the dynamics of the Asian summer monsoon, J. Geophys. Res.-Atmos., 121, 14159-14174, https://doi.org/10.1002/2016jd025616, 2016.

Peck, J., Gonzalez, L. A., Williams, L. R., Xu, W., Croteau, P. L., Timko, M. T., Jayne, J. T., Worsnop, D. R., Miake-Lye, R. C., and Smith, K. A.: Development of an aerosol mass spectrometer lens system for $\mathrm{PM}_{2.5}$, Aerosol Sci. Technol., 50, 781-789, https://doi.org/10.1080/02786826.2016.1190444, 2016.

Pitari, G., Mancini, E., and Bregman, A.: Climate forcing of subsonic aviation: Indirect role of sulfate particles via heterogeneous chemistry, Geophys. Res. Lett., 29, 14-11-14-14, https://doi.org/10.1029/2002GL015705, 2002.

Plane, J. M. C.: Atmospheric Chemistry of Meteoric Metals, Chem. Rev., 103, 4963-4984, https://doi.org/10.1021/cr0205309, 2003.

Plane, J. M. C.: Cosmic dust in the earth's atmosphere, Chem. Soc. Rev., 41, 6507-6518, https://doi.org/10.1039/C2CS35132C, 2012.

Plane, J. M. C., Feng, W., and Dawkins, E. C. M.: The Mesosphere and Metals: Chemistry and Changes, Chem. Rev., 115, 44974541, https://doi.org/10.1021/cr500501m, 2015.

Ploeger, F., Konopka, P., Walker, K., and Riese, M.: Quantifying pollution transport from the Asian monsoon anticyclone into the lower stratosphere, Atmos. Chem. Phys., 17, 7055-7066, https://doi.org/10.5194/acp-17-7055-2017, 2017.

Plumb, R. A., Heres, W., Neu, J. L., Mahowald, N. M., del Corral, J., Toon, G. C., Ray, E., Moore, F., and Andrews, A. E.: 
Global tracer modeling during SOLVE: High-latitude descent and mixing, J. Geophys. Res.-Atmos., 107, SOL 52-51-SOL 5214, https://doi.org/10.1029/2001JD001023, 2002.

Pruppacher, H. R. and Klett, J. D.: Microphysics of clouds and precipitation, 2nd Edn., Kluwer Academic Publishing, Dordrecht, 1997.

Qin, X., Bhave, P. V., and Prather, K. A.: Comparison of Two Methods for Obtaining Quantitative Mass Concentrations from Aerosol Time-of-Flight Mass Spectrometry Measurements, Anal. Chem., 78, 6169-6178, https://doi.org/10.1021/ac060395q, 2006.

Randel, W. J., Park, M., Emmons, L., Kinnison, D., Bernath, P., Walker, K. A., Boone, C., and Pumphrey, H.: Asian Monsoon Transport of Pollution to the Stratosphere, Science, 328, 611613, https://doi.org/10.1126/science.1182274, 2010.

Rapp, M. and Lübken, F.-J.: Polar mesosphere summer echoes (PMSE): Review of observations and current understanding, Atmos. Chem. Phys., 4, 2601-2633, https://doi.org/10.5194/acp-42601-2004, 2004.

Rapp, M., Strelnikova, I., Strelnikov, B., Hoffmann, P., Friedrich, M., Gumbel, J., Megner, L., Hoppe, U. P., Robertson, S., Knappmiller, S., Wolff, M., and Marsh, D. R.: Rocket-borne in situ measurements of meteor smoke: Charging properties and implications for seasonal variation, J. Geophys. Res.-Atmos., 115, D00I16, https://doi.org/10.1029/2009JD012725, 2010.

Rapp, M., Plane, J. M. C., Strelnikov, B., Stober, G., Ernst, S., Hedin, J., Friedrich, M., and Hoppe, U. P.: In situ observations of meteor smoke particles (MSP) during the Geminids 2010: constraints on MSP size, work function and composition, Ann. Geophys., 30, 1661-1673, https://doi.org/10.5194/angeo30-1661-2012, 2012.

Renard, J.-B., Berthet, G., Levasseur-Regourd, A.-C., Beresnev, S., Miffre, A., Rairoux, P., Vignelles, D., and Jégou, F.: Origins and Spatial Distribution of Non-Pure Sulfate Particles (NSPs) in the Stratosphere Detected by the Balloon-Borne Light Optical Aerosols Counter (LOAC), Atmosphere, 11, 1031, https://doi.org/10.3390/atmos11101031, 2020.

Robock, A.: Volcanic eruptions and climate, Rev. Geophys., 38, 191-219, https://doi.org/10.1029/1998rg000054, 2000.

Rosen, J. M.: The Boiling Point of Stratospheric Aerosols, J. Appl. Meteorol., 10, 1044-1046, https://doi.org/10.1175/15200450(1971)010<1044:tbposa>2.0.co;2, 1971.

Roth, A., Schneider, J., Klimach, T., Mertes, S., van Pinxteren, D., Herrmann, H., and Borrmann, S.: Aerosol properties, source identification, and cloud processing in orographic clouds measured by single particle mass spectrometry on a central European mountain site during HCCT-2010, Atmos. Chem. Phys., 16, 505524, https://doi.org/10.5194/acp-16-505-2016, 2016.

Saunders, R. W., Dhomse, S., Tian, W. S., Chipperfield, M. P., and Plane, J. M. C.: Interactions of meteoric smoke particles with sulphuric acid in the Earth's stratosphere, Atmos. Chem. Phys., 12, 4387-4398, https://doi.org/10.5194/acp-12-4387-2012, 2012.

Schneider, J.: Meteoric particles in the lower stratosphere: Data set, Max Planck Society, https://doi.org/10.17617/3.38, 2019.

Sedlacek, W. A., Mroz, E. J., Lazrus, A. L., and Gandrud, B. W.: A decade of stratospheric sulfate measurements compared with observations of volcanic-eruptions, J. Geophys. Res.-Oceans, 88, 3741-3776, https://doi.org/10.1029/JC088iC06p03741, 1983.
Shedlovsky, J. P. and Paisley, S.: On meteoritic component of stratospheric aerosols, Tellus, 18, 499-503, https://doi.org/10.3402/tellusa.v18i2-3.9362, 1966.

Subasinghe, D., Campbell-Brown, M. D., and Stokan, E.: Physical characteristics of faint meteors by light curve and high-resolution observations, and the implications for parent bodies, Mon. Not. R. Astron. Soc., 457, 1289-1298, https://doi.org/10.1093/mnras/stw019, 2016.

Thomson, D. S., Middlebrook, A. M., and Murphy, D. M.: Thresholds for laser-induced ion formation from aerosols in a vacuum using ultraviolet and vacuum-ultraviolet laser wavelengths, Aerosol Sci. Technol., 26, 544-559, https://doi.org/10.1080/02786829708965452, 1997.

Tritscher, I., Grooß, J.-U., Spang, R., Pitts, M. C., Poole, L. R., Müller, R., and Riese, M.: Lagrangian simulation of ice particles and resulting dehydration in the polar winter stratosphere, Atmos. Chem. Phys., 19, 543-563, https://doi.org/10.5194/acp19-543-2019, 2019.

Ulanovsky, A. E., Yushkov, V. A., Sitnikov, N. M., and Ravengnani, F.: The FOZAN-II Fast-Response Chemiluminescent Airborne Ozone Analyzer, Instrum. Exp. Tech.+, 44, 249-256, https://doi.org/10.1023/A:1017535608026, 2001.

Vernier, J. P., Pommereau, J. P., Garnier, A., Pelon, J., Larsen, N., Nielsen, J., Christensen, T., Cairo, F., Thomason, L. W., Leblanc, T., and McDermid, I. S.: Tropical stratospheric aerosol layer from CALIPSO lidar observations, J. Geophys. Res.-Atmos., 114, D00H10, https://doi.org/10.1029/2009JD011946, 2009.

Vogel, B., Müller, R., Günther, G., Spang, R., Hanumanthu, S., Li, D., Riese, M., and Stiller, G. P.: Lagrangian simulations of the transport of young air masses to the top of the Asian monsoon anticyclone and into the tropical pipe, Atmos. Chem. Phys., 19, 6007-6034, https://doi.org/10.5194/acp-19-6007-2019, 2019.

Voigt, C., Schlager, H., Luo, B. P., Dörnbrack, A., Roiger, A., Stock, P., Curtius, J., Vössing, H., Borrmann, S., Davies, S., Konopka, P., Schiller, C., Shur, G., and Peter, T.: Nitric Acid Trihydrate (NAT) formation at low NAT supersaturation in Polar Stratospheric Clouds (PSCs), Atmos. Chem. Phys., 5, 13711380, https://doi.org/10.5194/acp-5-1371-2005, 2005.

Voigt, C., Schumann, U., Graf, K., and Gottschaldt, K.-D.: Impact of rocket exhaust plumes on atmospheric composition and climate - an overview, Progress in Propulsion Physics, 4, 657-670, https://doi.org/10.1051/eucass/201304657, 2013.

Voigt, C., Schumann, U., Minikin, A., Abdelmonem, A., Afchine, A., Borrmann, S., Boettcher, M., Buchholz, B., Bugliaro, L., Costa, A., Curtius, J., Dollner, M., Dörnbrack, A., Dreiling, V., Ebert, V., Ehrlich, A., Fix, A., Forster, L., Frank, F., Fütterer, D., Giez, A., Graf, K., Grooß, J.-U., Groß, S., Heimerl, K., Heinold, B., Hüneke, T., Järvinen, E., Jurkat, T., Kaufmann, S., Kenntner, M., Klingebiel, M., Klimach, T., Kohl, R., Krämer, M., Krisna, T. C., Luebke, A., Mayer, B., Mertes, S., Molleker, S., Petzold, A., Pfeilsticker, K., Port, M., Rapp, M., Reutter, P., Rolf, C., Rose, D., Sauer, D., Schäfler, A., Schlage, R., Schnaiter, M., Schneider, J., Spelten, N., Spichtinger, P., Stock, P., Walser, A., Weigel, R., Weinzierl, B., Wendisch, M., Werner, F., Wernli, H., Wirth, M., Zahn, A., Ziereis, H., and Zöger, M.: ML-CIRRUS: The Airborne Experiment on Natural Cirrus and Contrail Cirrus with the High-Altitude Long-Range Research Aircraft HALO, B. Am. Meteorol. Soc., 98, 271-288, https://doi.org/10.1175/BAMS-D15-00213.1, 2017. 
von Hobe, M., Grooß, J.-U., Günther, G., Konopka, P., Gensch, I., Krämer, M., Spelten, N., Afchine, A., Schiller, C., Ulanovsky, A., Sitnikov, N., Shur, G., Yushkov, V., Ravegnani, F., Cairo, F., Roiger, A., Voigt, C., Schlager, H., Weigel, R., Frey, W., Borrmann, S., Müller, R., and Stroh, F.: Evidence for heterogeneous chlorine activation in the tropical UTLS, Atmos. Chem. Phys., 11, 241-256, https://doi.org/10.5194/acp-11-241-2011, 2011.

Weger, M., Heinold, B., Engler, C., Schumann, U., Seifert, A., Fößig, R., Voigt, C., Baars, H., Blahak, U., Borrmann, S., Hoose, C., Kaufmann, S., Krämer, M., Seifert, P., Senf, F., Schneider, J., and Tegen, I.: The impact of mineral dust on cloud formation during the Saharan dust event in April 2014 over Europe, Atmos. Chem. Phys., 18, 17545-17572, https://doi.org/10.5194/acp-1817545-2018, 2018.

Weigel, R., Volk, C. M., Kandler, K., Hösen, E., Günther, G., Vogel, B., Grooß, J.-U., Khaykin, S., Belyaev, G. V., and Borrmann, S.: Enhancements of the refractory submicron aerosol fraction in the Arctic polar vortex: feature or exception?, Atmos. Chem. Phys., 14, 12319-12342, https://doi.org/10.5194/acp-14-123192014, 2014.

Wilcox, L. J., Hoskins, B. J., and Shine, K. P.: A global blended tropopause based on ERA data. Part II: Trends and tropical broadening, Q. J. Roy. Meteor. Soc., 138, 576-584, https://doi.org/10.1002/qj.910, 2012.

Williams, L. R. and Long, F. S.: Viscosity of supercooled sulfuric acid solution, J. Phys. Chem., 99, 3748-3751, https://doi.org/10.1021/j100011a050, 1995.

Yu, P., Rosenlof, K. H., Liu, S., Telg, H., Thornberry, T. D., Rollins, A. W., Portmann, R. W., Bai, Z., Ray, E. A., Duan, Y., Pan, L. L., Toon, O. B., Bian, J., and Gao, R.-S.: Efficient transport of tropospheric aerosol into the stratosphere via the Asian summer monsoon anticyclone, P. Natl. Acad. Sci. USA, 114, 6972, https://doi.org/10.1073/pnas.1701170114, 2017.
Yue, G. K., Poole, L. R., Wang, P. H., and Chiou, E. W.: Stratospheric aerosol acidity, density, and refractive-index deduced from SAGE-II and NMC temperature data, J. Geophys. Res.Atmos., 99, 3727-3738, https://doi.org/10.1029/93jd02989, 1994.

Yushkov, V., Oulanovsky, A., Lechenuk, N., Roudakov, I., Arshinov, K., Tikhonov, F., Stefanutti, L., Ravegnani, F., Bonafe, U., and Georgiadis, T.: A Chemiluminescent Analyzer for Stratospheric Measurements of the Ozone Concentration (FOZAN), J. Atmos. Ocean. Tech., 16, 1345-1350, https://doi.org/10.1175/1520 0426(1999)016<1345:ACAFSM>2.0.CO;2, 1999.

Zahn, A. and Brenninkmeijer, C. A. M.: New directions: A chemical tropopause defined, Atmos. Environ., 37, 439-440, https://doi.org/10.1016/s1352-2310(02)00901-9, 2003.

Zahn, A., Weppner, J., Widmann, H., Schlote-Holubek, K., Burger, B., Kühner, T., and Franke, H.: A fast and precise chemiluminescence ozone detector for eddy flux and airborne application, Atmos. Meas. Tech., 5, 363-375, https://doi.org/10.5194/amt-5363-2012, 2012.

Zöger, M., Afchine, A., Eicke, N., Gerhards, M. T., Klein, E., McKenna, D. S., Mörschel, U., Schmidt, U., Tan, V., Tuitjer, F., Woyke, T., and Schiller, C.: Fast in situ stratospheric hygrometers: A new family of balloon-borne and airborne Lyman $\alpha$ photofragment fluorescence hygrometers, J. Geophys. Res.-Atmos., 104, 1807-1816, https://doi.org/10.1029/1998JD100025, 1999. 